\title{
Web crippling strength of cold-formed stainless steel lipped channels with web perforations under end-two-flange loading
}

\author{
Amir M. Yousefi' ${ }^{1}$, Asraf Uzzaman², James B.P. Lim ${ }^{1}$, G. Charles Clifton¹, \\ Ben Young ${ }^{3}$
}

\footnotetext{
${ }^{1}$ Department of Civil and Environmental Engineering, The University of Auckland, New Zealand

${ }^{2}$ Department of Mechanical and Aerospace Engineering, The University of Strathclyde, 75 Montrose Street, Glasgow G1 1XJ, UK

${ }^{3}$ Department of Civil Engineering, The University of Hong Kong, Pokfulam Road, Hong Kong

(Received: $\quad$; Revised: $\quad$; Accepted: $\quad$ )
}

\begin{abstract}
This paper presents a finite element investigation into the web crippling strength of cold-formed stainless steel lipped channels with circular web perforations under end-two-flange (ETF) loading. The cases of web openings located both centred and offset to the load bearing plates, are considered. In order to take into account the influence of the circular web openings, a parametric study involving 2,190 finite element analyses was performed, covering duplex EN1.4462, austenitic EN1.4404 and ferretic EN1.4003 stainless steel grades; from the results of the parametric study, strength reduction factor equations are determined. The strength reduction factor equations are first compared to equations recently proposed for cold-formed carbon steel lipped channels. It is demonstrated that the strength reduction factor equations proposed for cold-formed carbon steel are conservative for the stainless steel grades by up to $10 \%$. New coefficients for web crippling strength reduction factor equations are then proposed that can be applied to all three stainless steel grades.
\end{abstract}

Keywords: Cold-formed stainless steel; Finite element analysis; Lipped channel; Stainless steel material grades; Strength reduction factor; Web crippling; Web perforation. 


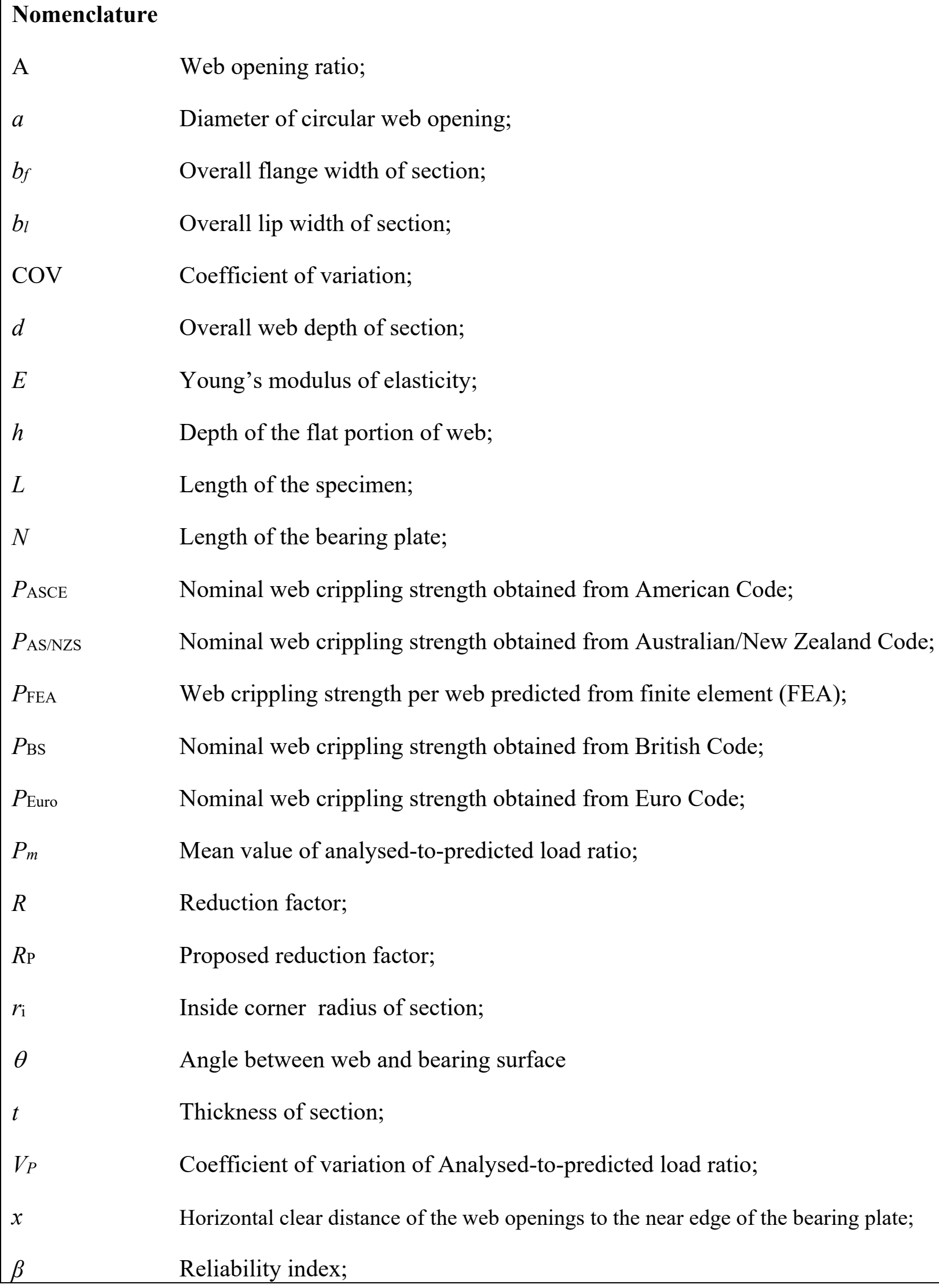




\section{Introduction}

Cold-formed stainless steel sections are most often used for both architectural and structural applications in conditions characterised by high corrosion aggressiveness; not only because they are aesthetically pleasing, but they also have favourable characteristics in terms of strength, durability and formability (Zhao et al. 2016; Nethercot et. al. 2011; Rosi et al. 2009). To provide ease of access for services, the use of web openings for such sections are also becoming popular in industry (Lawson et al. 2015) (see Fig. 1). Such web openings, however, result in the sections being more susceptible to web crippling, especially under concentrated loads in the vicinity of the openings.

The authors have recently proposed unified strength reduction factor equations for the web crippling strength of cold-formed stainless steel lipped channel-sections with circular web openings under the one and two flange loading conditions (Yousefi et al. 2016a, b, c, d). The equations covered three stainless steel grades: duplex grade EN 1.4462; austenitic grade EN 1.4404 and ferritic grade EN 1.4003. Similar equations for cold-formed carbon steel under end-one-flange loading condition have previously been proposed by Lian et al. (2016a, b), which was a continuation of the work of Uzzaman et al. (2012a, b, c, 2013) who had considered the two-flange loading conditions. When applied to the stainless steel grades, Yousefi et al. (2016b) showed that the equations proposed by Lian et al. (2016b) for the endone-flange (EOF) loading condition were unconservative by up to $7 \%$. Also, Yousefi et al. (2016d) showed that the equations proposed by Uzzaman et al. $(2012 \mathrm{a}, \mathrm{c})$ for the interior-twoflange (ITF) loading condition were unconservative by up to $17 \%$.

In the literature, for cold-formed stainless steel lipped channel-sections, only Krovink et al. (1995) has considered web crippling strength, but limited to sections without openings. Zhou and Young $(2006,2007,2008,2013)$ have considered the web crippling strength of cold-formed stainless steel tubular sections, again without openings. Research by Lawson et 
al. (2015), while concerned with circular web openings, focussed on the bending strength of the sections and not on the web crippling strength under concentrated loads (see Fig. 1).

In terms of cold-formed carbon steel, Keerthan and Mahendran (2012) and Keerthan et al. (2014) considered the web crippling strength of hollow flange channel beams, again without openings. Sundararajah et al. (2016) and Gunalan and Mahendran (2015) have also considered a Direct Strength Method approach for the web crippling strength of channel sections, again without openings. For cold-formed carbon steel lipped channel-sections, recent work has included Natario et al. (2014); Chen et al. (2015) and Gunalan and Mahendran (2015), all without openings.

This paper considers the case of the web crippling strength of cold-formed stainless steel lipped channels with circular web perforations under the end-two-flange (ETF) loading condition (see Figs. 2 and 3), and applicability of the proposed equations by Uzzaman et al. $(2012 \mathrm{c}, 2013)$ to the same three stainless steel grades, namely the duplex grade EN 1.4462; austenitic grade 1.4404 and ferritic grade 1.4003 . Similar to previous investigations, typical stress-strain curves for the three grades were taken from Chen and Young (2006) and Arrayago et. al. (2015).

\section{Experimental Investigation}

For cold-formed carbon steel, Uzzaman et al. (2012b, 2013) conducted 100 end-twoflange (ETF) laboratory tests on lipped channel-sections with circular web openings subjected to web crippling (see Fig. 3). The size of the circular web openings was varied in order to investigate the effect of the web openings on the web crippling strength. All the test specimens were fabricated with web openings located at the mid-depth of the webs with centred and offset to the bearing plates. The laboratory test results were used to validate a non-linear geometry elasto-plastic finite element model (details of the model can be found in Uzzaman 
et al. $(2012 b, 2013))$, which was then used for a parametric study to investigate the web crippling strength of cold-formed stainless steel lipped channel-sections with circular web openings under the end-two-flange (ETF) loading condition. Recommendations were proposed in the form of strength reduction factor equations, relating the loss of strength due to the web openings to the strength of the web without openings. The size of the circular web openings was varied in order to investigate the effect of the web opening size on the web crippling strength. Full details of both the laboratory tests can be found in Uzzaman et al. (2012b, 2013).

\section{Numerical Investigation}

\subsection{General}

In this study, the non-linear elasto-plastic general purpose finite element program ABAQUS (2014) was used to simulate the cold-formed stainless steel lipped channels with and without circular web perforations subjected to web crippling. The bearing plates, the lipped channel-section with circular web perforations and the interfaces between the bearing plates and the lipped-channel section were modelled. In the finite element model, the model was based on the centreline dimensions of the cross-sections. Details of the finite element models in ABAQUS (2014) are summarised below.

\subsection{Specimens labelling}

The dimensions of the lipped channel-section modelled are given in Table 1. Fig. 4 shows the definition of the symbols used to describe the dimensions of the cold-formed carbon steel lipped channel-sections considered in the test programme. The same definitions were used in this numerical investigation; the models have been coded such the nominal dimension of the model and the length of the bearing plates as well as the ratio of the diameter of the 
circular web perforations to the depth of the flat portion of the webs $(a / h)$ can be determined from the coding system. As an example, the label "142-N100-A0.2-FR" means the following. The first notation is the nominal depth of the models in millimeters. The notation "N100" indicates the length of bearing in millimeters (i.e. $100 \mathrm{~mm}$ ). The notation " $A 0.2$ " indicates the ratio of the diameter of the holes to the depth of the flat portion of the webs $(a / h)$ and are one of $0.2,0.4,0.6$ and 0.8 (i.e. $A 0.2$ means $a / h=0.2 ; A 0.4$ means $a / h=0.4$ etc). Channel-sections without circular web perforations are denoted by " $A O$ ". The flanges unfastened and fastened cases are identified as " $F R "$ and " $F X "$, respectively.

\subsection{Geometry and material properties}

In the finite element model, full model of the test set-up of Uzzaman et al. (2012b, 2013) was modelled, as shown in Fig 5. The stress-strain curves for duplex grade EN 1.4462; austenitic grade 1.4404 and ferritic grade 1.4003 were obtained from Chen and Young (2006) and Arrayago et al. (2015). The stress-strain curves were converted into true stress- strain curves as per the equations described in the ABAQUS manual (2014).

\subsection{Element type and mesh sensitivity}

Fig. 5 shows details of a typical finite element mesh of the channel section and the bearing plates. The effect of different element sizes in the cross-section of the channel section was investigated to provide both accurate results and reduced computation time. Finite element mesh sizes were $5 \mathrm{~mm} \times 5 \mathrm{~mm}$ for the cold-formed steel channel sections and $10 \mathrm{~mm}$ $\times 10 \mathrm{~mm}$ for the bearing plates.

Cold-formed steel lipped channels with and without web perforations were modelled using S4R shell element. The S4R is a four-node double curved thin or thick shell element with reduced integration and finite membrane strains. It is stated in the ABAQUS Manual (2014) 
that the S4R element is suitable for complex buckling behaviour. The S4R has six degrees of freedom per node and provides accurate solutions to most applications. The bearing plates and load transfer block were modelled using analytical rigid plates and C3D8R element, which is suitable for three-dimensional modelling of structures with plasticity, stress stiffening, large deflection, and large strain capabilities. The solid element is defined by eight nodes having three translational degrees of freedom at each node.

\subsection{Loading and boundary conditions}

Contact between the bearing plates and the cold-formed stainless steel section was modelled in ABAQUS using the contact pairs option. The interface between the bearing plates and the cold-formed stainless steel section were modelled using the surface-to-surface contact option. The bearing plates were the master surface, while the flange of the cross-section of stainless steel section was the slave surface extended up to the corners. Since the web-flange rounded transition will contact the bearing plates due to undergoing heavy deformation, the contact surfaces must include the corner elements and the flange. The two contact surfaces were not allowed to penetrate each other. The vertical load applied to the channel sections in the laboratory tests was modelled using displacement control method; an imposed displacement is applied to the nodes of the top bearing plate where the vertical load is applied. The top bearing plate was restrained against all degrees of freedom, except for the translational degree of freedom in the Y-direction. In the flanges fastened condition, the connector was used in the region where the flanges connected to the bearing plates. The nodes were prevented from translating in all degrees of freedom except in the y direction. Cartesian connectors were used to simulate the bolts instead of physically modelling bolts and holes. "CONN3D2" connector elements were used to model the in-plane translational stiffness i.e. $\mathrm{x}-$ and $\mathrm{z}$ directions. The stiffness of the connectors element was $10 \mathrm{kN} / \mathrm{mm}$, which Lim and Nethercot 
(2004a, b) suggestion would be suitable. In the y direction, the nodes were prevented from translating.

\subsection{Verification of finite element model}

In order to verify the finite element model, the results of experimental study on lipped carbon steel channel sections $142 \times 60 \times 13-\mathrm{t} 1.3-\mathrm{N} 30$ and $202 \times 65 \times 13-\mathrm{t} 1.4-\mathrm{N} 120$ (flanges unfastened and fastened to the bearing plates) for the cases of web holes located centred and offset to the bearing plates under ETF loading condition conducted by Uzzaman et al. (2012b, 2013) (see Fig. 3) were compared to the results obtained from the finite element analyses (Figs. 6 and 7) using the same material as developed for stainless steel materials in this study. As can be seen, there is good agreement between the failure loads of the tested specimens and the finite element results. For cold-formed stainless steel lipped channel-sections, the numerical failure loads with and without circular web perforations were then determined for the three stainless steel grades: duplex grade EN 1.4462; austenitic grade 1.4404 and ferritic grade 1.4003 (see Table 1). These results were compared with the failure loads calculated in accordance with ASCE 8-02 (2002), BS 5950-5 (1998), Eurocode-3 (2006), NAS (2007) and AS/NZS 4600 (2005) (see Table 2). The failure loads predicted from the finite element results are generally similar to the standard codified failure loads of the sections.

\section{Parametric study for stainless steel grades}

In this study, in order to investigate the effect of circular web perforations on the web crippling strength of cold-formed stainless steel lipped channels, a total of 2,190 finite element analyses of lipped channels with various dimensions and thicknesses were considered for the three stainless steel grades: duplex EN1.4462, austenitic EN1.4404 and ferritic EN1.4003. The web crippling strength predicted was influenced primarily by the ratio of the circular web opening depth to the flat portion of the web, the ratio of the bearing length to the flat portion 
of the web and the location of the web hole as defined by the distance of the web perforation from the edge of the bearing divided by the flat portion of the web (Uzzaman et al. (2012a,b,c, 2013)). In order to find the effect of $a / h, N / h$ and $x / h$ on the web crippling strength of channel sections with circular web perforations, parametric studies were carried out considering the circular web perforations, different bearing plate lengths, the cross-section sizes and location of the circular web perforations. The cases of both flanges fastened and flanges unfastened to the bearing plates were considered.

The specimens consisted of three different section sizes, having thicknesses $(t)$ ranging from $1.23 \mathrm{~mm}$ to $6.0 \mathrm{~mm}$ and web slenderness $(\mathrm{h} / \mathrm{t})$ values ranging from 111.7 to 157.8 . The ratios of the diameter of the circular web perforations (a) to the depth of the flat portion of the webs $(\mathrm{h})$ were $0.2,0.4,0.6$ and 0.8 . The ratios of the distance of the web perforations $(\mathrm{x})$ to the depth of the flat portion of the web (h) were 0.2, 0.4 and 0.6. Bearing plates of lengths $(\mathrm{N})$ equal to $100 \mathrm{~mm}, 120 \mathrm{~mm}$ and $150 \mathrm{~mm}$ are considered. For each series of specimens, the web crippling strengths of the sections without the web perforations were obtained. Thus, the ratio of the web crippling strengths for sections with web perforations divided by the sections without web perforations, which is the strength reduction factor (R), was used to quantify the degrading influence of the web perforations on the web crippling strengths.

The parametric study investigated the effect of the ratios of $a / h, N / h$ and $x / h$. The web crippling strengths (PFEA) per web predicted from the FEA are summarised in Tables 3 to 5 for the duplex grade EN 1.4462. As can be seen from Tables 3 to 5, the failure load of the cold-formed stainless steel sections reduces as web perforations are present and continues to reduce with increase in the size of web perforations. The results demonstrate that the failure load obtained from the cold-formed stainless steel sections with the case of flanges fastened to bearing plates is in average $25 \%$ higher than the case of flanges unfastened to bearing plates for the sections with and without web perforations. In addition, for the case of web 
perforations with a horizontal clear distance to the near edge of the bearing plates, the web crippling strength of the sections is higher than the case of web holes located centred above the bearing plates. Moreover, for the same section with different span and bearing plates, the failure loads were found to be different among the results. Based on the results, it was found that the failure load increases as the length of the bearing plates increases and as the length of the sections increases. The effect of the ratios of $a / h, N / h$ and $x / h$ on the reduction factor of the web crippling strength is shown in Fig. 8 for the C142 specimen.

Fig. 8(a) shows the ratio of the circular web perforation depth to the flat portion of the web $(a / h)$ versus the strength reduction factor, for the three stainless steel grades. As can be seen, the reduction in strength increases as the parameter $a / h$ increases for all three stainless steels, in particular for the ferritic grade with lower thickness $(1.3 \mathrm{~mm})$. The reduction in strength of the ferritic grade $6 \mathrm{~mm}$ thick section is smallest and the reduction in strength increases as the section becomes thinner. It can be seen that when the $a / h$ ratio increases from 0.2 to 0.6 , the reduction in strength for the ferritic grade increases by $28 \%$.

Fig. $8(\mathrm{~b})$ shows the ratio of the bearing length to the flat portion of the web $(N / h)$ versus the strength reduction factor, for the three stainless steel grades. As can be seen, the reduction in strength is not sensitive to the ratio $N / h$ and the $6 \mathrm{~mm}$ thick sections have the smallest reduction in strength or the highest strength reduction factor.

Fig. 8(c) shows the ratio of the circular web hole location to the flat portion of the web $(x / h)$ versus the strength reduction factor, for the three stainless steel grades. As can be seen, the reduction in strength is sensitive to the horizontal distance of the web perforations to the bearing plates. As the ratio of $x / h$ decreases from 0.6 to 0.2 , the strength reduction factor decreases by $7 \%$. Also, it can again be seen that the reduction in strength is less for the austenitic grade compared to that of the other two stainless steel grades. 


\section{Reduction factor comparison with Uzzaman et al. (2012c, 2013)}

For ease of reference, the reduction factor equations proposed by Uzzaman et al. (2012c, 2013) are summarised below:

For centered web opening:

Free case $\quad R_{P}=0.90-0.60\left(\frac{a}{h}\right)+0.12\left(\frac{N}{h}\right) \leq 1$

Fixed case $\quad R_{P}=0.95-0.50\left(\frac{a}{h}\right)+0.08\left(\frac{N}{h}\right) \leq 1$

For offset web opening:

Free case $\quad R_{P}=0.95-0.49\left(\frac{a}{h}\right)+0.17\left(\frac{x}{h}\right) \leq 1$

Fixed case: $\quad R_{P}=0.96-0.36\left(\frac{a}{h}\right)+0.14\left(\frac{x}{h}\right) \leq 1$

where the limits for the reduction factor in Eqs. (1)-(4) are $h / t \leq 156, N / t \leq 84$, $N / h \leq 0.63, a / h \leq 0.8$, and $\theta=90^{\circ}$.

In order to evaluate the applicability of the proposed equations to cold-formed stainless steel grades, an extensive statistical analysis was performed on all four proposed equations. Table 6 compares the reduction factors determined from the finite element models to Eqs. (1)(4) for cases of centred and offset web perforation where the flanges are unfastened to the bearing plates.

As can be seen from Table 6, the four equations proposed by Uzzaman et al. (2012c, 2013) for carbon steel are conservative for the stainless steel grades, especially for the ferritic stainless steel grade which are conservative by up to $10 \%$. As an example, for the ferritic stainless steel grade, for the centred web perforation case, the mean value of the web crippling reduction factors are 1.10 and 1.00 for the cases of flanges unfastened and fastened to the bearing plates, respectively; the corresponding values of COV are 0.05 and 0.10 , respectively. 
Similar values nearly are reported for the case of the duplex stainless steel grade. In the next section, new equations are proposed for each of the three stainless steel grades.

\section{Proposed strength reduction factors}

Tables 3 to 5 show the dimensions considered and web crippling strengths of the stainless steel sections predicted from the finite element analysis. Using bivariate linear regression analysis, two unified strength reduction factor equations $\left(R_{\mathrm{p}}\right)$ for three stainless steel grades with web openings are proposed. The equations are as follows:

$$
\begin{array}{ll}
\text { Centred web opening: } & R_{p}=\alpha-\gamma\left(\frac{a}{h}\right)+\lambda\left(\frac{N}{h}\right) \leq 1 \\
\text { Offset web opening: } & R_{p}=\rho-\mu\left(\frac{a}{h}\right)-\zeta\left(\frac{x}{h}\right) \leq 1
\end{array}
$$

The limits for the reduction factor Eqs. (5)-(6) are $h / t \leq 157.68, N / t \leq 120.97, N / h \leq 1.15$, $a / h \leq 0.8$, and $\theta=90^{\circ}$. The coefficients $\alpha, \gamma, \lambda, \rho, \mu$ and $\zeta$ of the equations are calibrated with the stainless steel finite element analysis results, and the coefficients are presented in Table 7.

\section{Comparison of numerical results with proposed reduction factors}

For the three stainless steels grades, the values of the strength reduction factor $(R)$ obtained from the numerical results are compared with the values of the proposed strength reduction factor $\left(R_{p}\right)$ calculated using Eqs. (5) and (6). The results for C142, C202 and C302 are shown in Figs. 9 to 12. In order to evaluate the accuracy of proposed equations, extensive statistical reliability analyses are performed. The results are summarized in Table 8 . It should be noted, in calculating the reliability index, the resistance factor of $\phi=0.85$ was used, corresponding to the reliability index $\beta$ from the North American Specification (NAS, 2007). The load combination of $1.2 \mathrm{DL}+1.6 \mathrm{LL}$ as specified in the NAS specification was used in the 
reliability analysis, where DL is the dead load and LL is the live load. In this study, $M_{m}=1.10$ and $V_{M}=0.10$, which are the mean and coefficients of variation for the material properties factors, $F_{m}=1.00$ and $V_{F}=0.05$, which are the mean and coefficients of variation for the fabrication factors, and $V_{q}=0.21$, which is the coefficient of variation of load effect were used. According to the NAS specification, design rules are reliable if the reliability index is more than 2.5. As can be seen in Table 8, the proposed reduction factors are a good match with the numerical results for the both cases of flanges unfastened and flanges fastened to the bearing plates.

For example, for the centred circular web perforation, the mean value of the web crippling reduction factor ratios are 1.00 and 1.00 for the cases of flanges unfastened and flanges fastened to the bearing plates, respectively. The corresponding values of COV are 0.10 and 0.13 , respectively. Similarly, the reliability index values $(\beta)$ are 2.62 and 2.51 , respectively. For the offset circular web perforation, the mean value of the web crippling reduction factor ratios are 1.00 and 1.00 for the cases of flanges unfastened and flanges fastened to the bearing plates, respectively. The corresponding values of COV are 0.02 and 0.01 , respectively. Similarly, the reliability index values $(\beta)$ are 2.84 and 2.85 , respectively. Therefore, the proposed strength reduction factor equations are able to reliably predict the influence of the circular web perforations on the web crippling strengths of cold-formed stainless steel lipped channels under end-two-flange (ETF) loading.

\section{Conclusions}

In this paper, an investigation into the effect of circular web perforations on the web crippling strength of cold-formed stainless steel lipped channels has been conducted. For this purpose, a parametric study comprising 2,190 lipped channels with various dimensions, thicknesses were considered for the three stainless steel grades, namely the duplex EN1.4462, 
austenitic EN1.4404 and ferretic EN1.4003. Cases with and without circular web perforations under the end-two-flange (ETF) loading were considered with web holes located centred and offset to the bearing plates.

In order to take into account the influence of the circular web perforations, strength reduction factor equations were determined. The strength reduction factor equations were then compared to equations proposed by Uzzaman et al. (2012c, 2013) for cold-formed carbon steel. It was observed that the strength reduction factor equations proposed for cold-formed carbon steel are conservative for the stainless steel grades by up to $10 \%$.

Based on the finite element results obtained from this study, new coefficients for web crippling strength reduction factor equations considering different web hole diameter and location in the web were proposed for both cases of flanges unfastened and flanges fastened to the bearing plates under end-two-flange (ETF) loading. Reliability analyses were performed in order to evaluate the reliability of the proposed strength reduction factors. It was demonstrated that the proposed strength reduction factors are generally conservative and agree well with the finite element results. The proposed new unified strength reduction factors are capable to produce reliable and safe yet not too conservative design values when calibrated with the resistance factor of 0.85 ( $\varphi=0.85$ ) for end-two-flange (ETF) loading. 


\section{Acknowledgement}

The University of Auckland Doctoral Scholarship is greatly acknowledged.

\section{Declaration of Conflicting Interests}

The author(s) declared no potential conflicts of interest with respect to the research, authorship and/or publication of this article.

\section{Funding}

The author(s) received no financial support for the research, authorship and/or publication of this article. 


\section{References}

ABAQUS. (2014), Analysis User's Manual-Version 6.14-2 ABAQUS Inc., USA.

Arrayago, I., E. Real, L. Gardner (2015), "Description of stress-strain curves for stainless steel alloys", Materials \& Design, 87, 540-552.

AS/NZS 4600 (2005), Cold-formed steel structures: AS/NZS 4600:2005, Standards Australia, Sydney, Australia.

ASCE 8-02 (2002), Specification for the Design of Cold-Formed Stainless Steel Structural Members: SEI/ASCE 8-02, Reston, VA.

BS 5950-5 (1998), Structural use of steelwork in buildings, Part 5 Code of practice for the design of cold-formed sections. British Standards Institution, London.

Chen, J., and Ben Young (2006), "Stress-strain curves for stainless steel at elevated temperatures", Engineering Structures, 28(2), 229-239.

Chen, Y., Xixiang Chen, Chaoyang Wang (2015), "Experimental and finite element analysis research on cold-formed steel lipped channel beams under web crippling", ThinWalled Structures, 87, 41-52.

Gunalan, S., M. Mahendran (2015), "Web crippling tests of cold-formed steel channels under two flange load cases", Journal of Constructional Steel Research, 110, 1-15.

Eurocode-3 (2006), Design of steel structures: Part 1.3: General rules - Supplementary rules for cold-formed thin gauge members and sheeting, in: ENV 1993-1-3, European Committee for Standardization, Brussels, Belgium.

Keerthan, P., and Mahen Mahendran (2012), "Shear behaviour and strength of LiteSteel beams with web openings", Advances in Structural Engineering, 15(2), 171-184.

Keerthan, P., Mahen Mahendran, Edward Steau (2014), "Experimental study of web crippling behaviour of hollow flange channel beams under two flange load cases", Thin-Walled Structures, 85, 207-219.

Korvink, S.A., G.J. van den Berg, P. van der Merwe (1995), "Web crippling of stainless steel cold-formed beams", Journal of Constructional Steel Research, 34 (2-3), 225248.

Lawson, R. M., Antonio Basta, Assraf Uzzaman (2015), "Design of stainless steel sections with circular openings in shear", Journal of Constructional Steel Research, 112, 228241. 
Lian, Y., Uzzaman A., Lim J.B.P., Abdelal G., Nash D., Young B. (2016a), "Effect of web holes on web crippling strength of cold-formed steel channel sections under end-oneflange loading condition - Part I: Tests and finite element analysis", Thin-Walled Structures, 107, 443-452

Lian, Y., Uzzaman A., Lim J.B.P., Abdelal G., Nash D., Young B. (2016b), "Effect of web holes on web crippling strength of cold-formed steel channel sections under end-oneflange loading condition - Part II: Parametric study and proposed design equations", Thin-Walled Structures, 107, 489-501.

Lim, J.B.P., and Nethercot, D.A. (2004a). "Finite element idealisation of a cold-formed steel portal frame", Journal of Structural Engineering, 130:1, pp.78-94.

Lim, J.B.P., and Nethercot, D.A. (2004b). "Stiffness prediction for bolted momentconnections between cold-formed steel members", Journal of Constructional Steel Research, 60:1, pp.85-107.

NAS (2007), North American Specification for the Design of Cold-Formed Steel Structural Members: American Iron and Steel Institute, AISI S100-2007, AISI Standard.

Natário, P., N. Silvestre, D. Camotim (2014), "Web crippling failure using quasi-static FE models", Thin-Walled Structures, 84, 34-49.

Nethercot, D. A., Salih, E. L. and Gardner, L. (2011). "Behaviour and design of stainless steel bolted connections", Advances in Structural Engineering, Vol. 14, No. 4, pp. 647-658.

Rossi, B., Jaspart, J. P., \& Rasmussen, K. J. (2009), Combined distortional and overall flexural-torsional buckling of cold-formed stainless steel sections: design. Journal of structural engineering, 136(4), 361-369.

Sundararajah, L., Mahendran, M., Keerthan, P. (2016). Experimental Studies of Lipped Channel Beams Subject to Web Crippling under Two-Flange Load Cases. Journal of Structural Engineering, 04016058.

Uzzaman, A., James B.P. Lim, David Nash, Jim Rhodes, Ben Young (2012a), "Web crippling behaviour of cold-formed steel channel sections with offset web holes subjected to interior-two-flange loading", Thin-Walled Structures, 50, 76-86.

Uzzaman, A., James B.P. Lim, David Nash, Jim Rhodes, Ben Young (2012b), "Cold-formed steel sections with web openings subjected to web crippling under two-flange loading conditions-part I: Tests and finite element analysis", Thin-Walled Structures, 56, 38-48. 
Uzzaman, A., James B.P. Lim, David Nash, Jim Rhodes, Ben Young (2012c), "Cold-formed steel sections with web openings subjected to web crippling under two-flange loading conditions-part II: Parametric study and proposed design equations", ThinWalled Structures, 56, 79-87.

Uzzaman, A., James B.P. Lim, David Nash, Jim Rhodes, Ben Young (2013), "Effect of offset web holes on web crippling strength of cold-formed steel channel sections under end-two-flange loading condition", Thin-Walled Structures, 65, 34-48.

Yousefi, A. M., James B.P. Lim, Asraf Uzzaman, Ying Lian, G. Charles Clifton, Ben Young (2016a), "Web crippling strength of cold-formed stainless steel lipped channelsections with web openings subjected to Interior-One-Flange loading condition", Steel and Composite Structures, 21 (3), 629-659.

Yousefi, A. M., James B.P. Lim, Asraf Uzzaman, Ying Lian, G. Charles Clifton, Ben Young (2016b), "Design of cold-formed stainless steel lipped channel-sections with web openings subjected to web crippling under End-One-Flange loading condition", Advances in Structural Engineering, 20(11), 1-22.

Yousefi, A. M., James B.P. Lim, Asraf Uzzaman, Ying Lian, G. Charles Clifton, Ben Young (2016c), "Web Crippling Strength of Cold-Formed Duplex Stainless Steel Lipped Channel-Sections with Web Openings Subjected to Interior-One-Flange Loading Condition", Proceeding of The Wei-Wen Yu International Specialty Conference on Cold-Formed Steel Structures, Baltimore, Maryland, USA.

Yousefi, A. M., Asraf Uzzaman, James B.P. Lim, G. Charles Clifton, Ben Young (2016d), "Numerical investigation of web crippling strength in cold-formed stainless steel lipped channels with web openings subjected to interior-two-flange loading condition", Steel and Composite Structures, revised.

Zhao, O., Leroy Gardner, Ben Young, (2016), Buckling of ferritic stainless steel members under combined axial compression and bending, Journal of Constructional Steel Research, Vol. 117, pp. 35-48.

Zhou, F., and Ben Young (2006), "Yield line mechanism analysis on web crippling of coldformed stainless steel tubular sections under two-flange loading", Engineering Structures, 28(6), 880-892.

Zhou, F., and Ben Young (2007), "Cold-formed high-strength stainless steel tubular sections subjected to web crippling", Journal of structural engineering, 133(3), 368-377. 
Zhou, F., and Ben Young (2008), "Web crippling of cold-formed stainless steel tubular sections", Advances in Structural Engineering, 11(6), 679-691.

Zhou, F., and Ben Young (2013), "Web crippling behaviour of cold-formed duplex stainless steel tubular sections at elevated temperatures", Engineering Structures, 57, 51-62. 


\section{List of tables}

Table 1 Dimensions and web crippling strengths predicted from finite element analysis of cold-formed stainless steel lipped channels

(a) For the case of flanges unfastened to the bearing plates

(b) For the case of flanges fastened to the bearing plates

Table 2 Comparison of numerical results with design strengths for the case of flanges fastened to bearing plates without web hole

Table 3 Web crippling strengths of duplex stainless steel sections predicted from finite element analysis: $a / h$ for centred circular web perforation

Table 4 Web crippling strengths of duplex stainless steel sections predicted from finite element analysis: $a / h$ for offset circular web perforation

Table 5 Web crippling strengths of duplex stainless steel sections predicted from finite element analysis: $x / h$ for offset circular web perforation

Table 6 Comparison of web crippling strength reduction factor for cold-formed stainless steel lipped channels with reduction factors equations proposed by Uzzaman et al. (2012c, 2013)

(a) Flanges unfastened to the bearing plates

(b) Flanges fastened to the bearing plates

Table 7 Coefficients of the proposed strength reduction factor equations

Table 8 Statistical analysis of strength reduction factor for three stainless steel grades 
Table 1 Dimensions and web crippling strengths predicted from finite element analysis of cold-formed stainless steel lipped channels

(a) For the case of flanges unfastened to the bearing plates

\begin{tabular}{|c|c|c|c|c|c|c|c|c|c|c|c|c|c|c|c|}
\hline \multirow[t]{2}{*}{ Specimen } & \multirow{2}{*}{$\begin{array}{c}\text { Web } \\
d \\
(m m)\end{array}$} & \multicolumn{2}{|c|}{ Flange Lip } & \multirow{2}{*}{$\begin{array}{c}\text { Thickness } \\
t \\
(\mathrm{~mm})\end{array}$} & \multirow{2}{*}{$\begin{array}{c}\text { Length } \\
\\
L \\
(\mathrm{~mm})\end{array}$} & \multirow{2}{*}{$\begin{array}{c}\text { Web } \\
\text { opening } \\
a \\
(\mathrm{~mm})\end{array}$} & \multicolumn{3}{|c|}{ Duplex } & \multicolumn{3}{|c|}{ Ferritic } & \multicolumn{3}{|c|}{ Austenitic } \\
\hline & & $\begin{array}{c}b_{f} \\
(\mathrm{~mm})\end{array}$ & $\begin{array}{c}b_{l} \\
(\mathrm{~mm})\end{array}$ & & & & $\begin{array}{r}P(A 0) \\
(k N)\end{array}$ & $\begin{array}{l}\text { P(Opening) } \\
(\mathrm{kN})\end{array}$ & $\begin{array}{l}\text { P(Opening) } \\
(k N)\end{array}$ & $\begin{array}{l}P(A 0) \\
(k N)\end{array}$ & $\begin{array}{l}P(\text { Opening }) \\
(k N)\end{array}$ & $\begin{array}{l}P(\text { Opening }) \\
(k N)\end{array}$ & $\begin{array}{l}P(A 0) \\
(k N)\end{array}$ & $\begin{array}{l}P(\text { Opening }) \\
(k N)\end{array}$ & $\begin{array}{l}\text { P(Opening }) \\
(\mathrm{kN})\end{array}$ \\
\hline & & & & & & & & Offset & Centred & & Offset & Centred & & Offset & Centred \\
\hline 142-N100-MA0.6-FR & 141.82 & 60.63 & 13.66 & 1.27 & 720.0 & 139.27 & 3.34 & 3.25 & 2.28 & 3.03 & 2.95 & 2.05 & 2.75 & 2.68 & 1.88 \\
\hline 142-N120-MA0.6-FR & 142.24 & 60.37 & 13.90 & 1.27 & 740.0 & 139.70 & 3.61 & 3.53 & 2.47 & 3.02 & 3.19 & 2.21 & 2.95 & 2.89 & 2.04 \\
\hline 202-N100-MA0.4-FR & 202.04 & 64.79 & 14.78 & 1.38 & 899.2 & 199.28 & 3.05 & 2.98 & 2.33 & 2.82 & 2.76 & 2.16 & 2.61 & 2.54 & 2.02 \\
\hline 202-N100-MA0.6-FR & 202.04 & 64.79 & 14.78 & 1.38 & 899.2 & 199.28 & 3.05 & 2.89 & 2.02 & 2.82 & 2.66 & 2.02 & 2.61 & 2.46 & 1.80 \\
\hline 202-N120-MA0.4-FR & 202.00 & 65.00 & 14.73 & 1.38 & 920.0 & 199.24 & 3.23 & 3.17 & 2.49 & 2.98 & 2.92 & 2.3 & 2.74 & 2.69 & 2.14 \\
\hline 202-N120-MA0.6-FR & 202.00 & 65.00 & 14.73 & 1.38 & 920.0 & 199.24 & 3.23 & 3.07 & 2.06 & 2.98 & 2.83 & 2.06 & 2.74 & 2.62 & 1.82 \\
\hline 202-N150-MA0.4-FR & 202.01 & 65.04 & 14.98 & 1.38 & 950.0 & 199.24 & 3.49 & 3.41 & 2.73 & 3.2 & 3.12 & 2.49 & 2.74 & 2.9 & 2.31 \\
\hline 302-N120-MA0.6-FR & 303.07 & 87.95 & 18.26 & 1.90 & 1221.0 & 299.26 & 5.66 & 5.25 & 3.69 & 5.66 & 5.11 & 3.51 & 5.77 & 4.76 & 3.70 \\
\hline 302-N150-MA0.6-FR & 303.03 & 88.54 & 18.97 & 1.90 & 1249.0 & 299.23 & 6.04 & 5.93 & 3.79 & 5.67 & 5.36 & 3.79 & 6.19 & 5.11 & 3.80 \\
\hline
\end{tabular}


(b) For the case of flanges fastened to the bearing plates

\begin{tabular}{|c|c|c|c|c|c|c|c|c|c|c|c|c|c|c|c|}
\hline \multirow[t]{2}{*}{ Specimen } & \multirow{2}{*}{$\begin{array}{c}\text { Web } \\
\quad \begin{array}{c}d \\
(\mathrm{~mm})\end{array}\end{array}$} & \multirow{2}{*}{$\begin{array}{c}\text { Flange } \\
\qquad \begin{array}{c}b_{f} \\
(\mathrm{~mm})\end{array}\end{array}$} & \multirow{2}{*}{$\begin{array}{l}\text { Lip } \\
\qquad \begin{array}{c}b_{l} \\
(\mathrm{~mm})\end{array}\end{array}$} & \multirow{2}{*}{$\begin{array}{c}\text { Thickness } \\
t \\
(\mathrm{~mm})\end{array}$} & \multirow{2}{*}{$\begin{array}{c}\text { Length } \\
\qquad \\
\quad \begin{array}{c}(\mathrm{mm})\end{array}\end{array}$} & \multirow{2}{*}{$\begin{array}{c}\text { Web } \\
\text { opening } \\
a \\
(\mathrm{~mm})\end{array}$} & \multicolumn{3}{|c|}{ Duplex } & \multicolumn{3}{|c|}{ Ferritic } & \multicolumn{3}{|c|}{ Austenitic } \\
\hline & & & & & & & $\begin{array}{c}P(A 0) \\
(k N)\end{array}$ & $\begin{array}{l}\text { P(Opening) } \\
(k N)\end{array}$ & $\begin{array}{l}P(\text { Opening }) \\
(k N)\end{array}$ & $\begin{array}{l}P(A 0) \\
(k N)\end{array}$ & $\begin{array}{l}\text { P(Opening }) \\
(k N)\end{array}$ & $\begin{array}{l}\text { P(Opening }) \\
(k N)\end{array}$ & $\begin{array}{l}P(A 0) \\
(k N)\end{array}$ & $\begin{array}{l}\text { P(Opening }) \\
(k N)\end{array}$ & $\begin{array}{l}P(\text { Opening }) \\
(k N)\end{array}$ \\
\hline & & & & & & & & Offset & Centred & & Offset & Centred & & Offset & Centred \\
\hline 142-N100-MA0.6-FX & 142.49 & 60.33 & 13.79 & 1.29 & 720.0 & 139.27 & 5.58 & 5.55 & 4.13 & 4.73 & 4.69 & 3.56 & 4.35 & 4.27 & 3.28 \\
\hline 142-N120-MA0.6-FX & 142.38 & 60.21 & 13.68 & 1.29 & 740.0 & 139.70 & 6.19 & 6.16 & 4.65 & 6.18 & 5.20 & 3.96 & 4.84 & 4.76 & 3.68 \\
\hline 142-N150-MA0.4-FX & 142.18 & 60.12 & 13.19 & 1.28 & 770.0 & 139.84 & 7.12 & 7.10 & 6.08 & 8.05 & 6.04 & 4.77 & 5.61 & 5.58 & 4.85 \\
\hline 202-N100-MA0.4-FX & 201.99 & 64.87 & 14.76 & 1.37 & 900.0 & 199.28 & 5.27 & 5.24 & 4.29 & 4.58 & 4.57 & 3.75 & 4.30 & 4.28 & 3.53 \\
\hline 202-N100-MA0.6-FX & 201.99 & 64.87 & 14.76 & 1.37 & 900.0 & 199.28 & 5.27 & 5.18 & 3.52 & 4.58 & 4.55 & 3.52 & 4.30 & 4.24 & 2.98 \\
\hline 202-N120-MA0.4-FX & 202.05 & 64.99 & 14.82 & 1.41 & 920.0 & 199.24 & 5.72 & 5.69 & 4.69 & 4.96 & 4.94 & 4.09 & 4.64 & 4.62 & 3.83 \\
\hline 202-N120-MA0.6-FX & 202.05 & 64.99 & 14.82 & 1.41 & 920.0 & 199.24 & 5.72 & 5.64 & 3.63 & 4.96 & 4.92 & 3.29 & 4.64 & 4.59 & 3.06 \\
\hline 202-N150-MA0.4-FX & 202.00 & 64.93 & 15.00 & 1.41 & 950.0 & 199.24 & 6.43 & 6.38 & 5.33 & 5.57 & 5.55 & 4.67 & 5.43 & 5.20 & 4.33 \\
\hline 302-N100-MA0.6-FX & 303.20 & 88.24 & 18.66 & 1.96 & 1199.0 & 299.37 & 9.56 & 9.30 & 6.55 & 8.40 & 8.21 & 6.02 & 7.99 & 7.83 & 5.68 \\
\hline 302-N120-MA0.6-FX & 303.50 & 88.53 & 18.36 & 1.93 & 1219.0 & 299.26 & 10.17 & 3.52 & 6.71 & 8.93 & 8.78 & 6.16 & 8.47 & 8.40 & 5.21 \\
\hline 302-N150-MA0.6-FX & 303.85 & 88.71 & 18.41 & 1.90 & 1248.3 & 299.23 & 11.14 & 10.98 & 6.94 & 9.80 & 9.74 & 6.35 & 9.31 & 9.26 & 6.20 \\
\hline
\end{tabular}


Table 2 Comparison of numerical results with design strengths for the case of flanges fastened to bearing plates without web hole

\begin{tabular}{|c|c|c|c|c|c|c|c|c|c|c|c|c|c|c|c|}
\hline \multirow[t]{2}{*}{ Specimen } & \multirow{2}{*}{$\begin{array}{l}\text { Web } \\
\text { slenderness } \\
h / t\end{array}$} & \multirow{2}{*}{$\begin{array}{l}\text { Bearing } \\
\text { length to } \\
\text { thickness } \\
\text { ratio }\end{array}$} & \multirow{2}{*}{$\begin{array}{l}\text { Bearing } \\
\text { length to } \\
\text { web height } \\
\text { ratio } \\
N / h\end{array}$} & \multirow{2}{*}{$\begin{array}{l}\text { Inside bend } \\
\text { radius ratio } \\
r_{i} / t\end{array}$} & \multirow{2}{*}{$\begin{array}{l}\text { Failure } \\
\text { load per } \\
\text { web } \\
\mathrm{P}_{\mathrm{FEA}} \\
(k N)\end{array}$} & \multicolumn{6}{|c|}{$\begin{array}{l}\text { Web crippling strength per web } \\
\text { predicted from current design codes }\end{array}$} & \multicolumn{4}{|c|}{ Comparison } \\
\hline & & & & & & $\begin{array}{l}\mathrm{P}_{\mathrm{NAS}} \\
(k N)\end{array}$ & $\begin{array}{c}\mathrm{P}_{\mathrm{ASCE}} \\
(k N)\end{array}$ & $\begin{array}{l}\mathrm{P}_{\mathrm{BS}} \\
(k N)\end{array}$ & $\begin{array}{l}\mathrm{P}_{\text {Euro }} \\
(k N)\end{array}$ & $\mathrm{P}_{\mathrm{AS} / \mathrm{NZS}}$ & $\mathrm{P} / \mathrm{P}_{\mathrm{NAS}}$ & $\mathrm{P} / \mathrm{P}_{\mathrm{ASCE}}$ & $\mathrm{P} / \mathrm{P}_{\mathrm{AS} / \mathrm{NZS}}$ & $\mathrm{P} / \mathrm{P}_{\mathrm{BS}}$ & $\mathrm{P} / \mathrm{P}_{\text {Euro }}$ \\
\hline 142-N100-A0 & 114.01 & 81.30 & 0.71 & 3.90 & 2.94 & 3.12 & 2.56 & 2.37 & 2.54 & 3.12 & 0.94 & 1.15 & 0.94 & 1.24 & 1.16 \\
\hline 142-N120-A0 & 111.67 & 96.01 & 0.86 & 3.84 & 3.05 & 3.24 & 2.73 & 2.52 & 2.78 & 3.24 & 0.94 & 1.12 & 0.94 & 1.21 & 1.10 \\
\hline 142-N150-A0 & 112.64 & 120.97 & 1.07 & 3.87 & 3.37 & 3.44 & 3.06 & 2.82 & 3.26 & 3.44 & 0.98 & 1.10 & 0.98 & 1.20 & 1.03 \\
\hline 202-N100-A0 & 147.62 & 74.07 & 0.50 & 3.70 & 3.17 & 2.94 & 2.52 & 2.49 & 2.62 & 2.94 & 1.08 & 1.26 & 1.08 & 1.27 & 1.21 \\
\hline 202-N120-A0 & 147.68 & 88.89 & 0.60 & 3.70 & 3.41 & 3.27 & 2.97 & 2.93 & 3.19 & 3.27 & 1.04 & 1.15 & 1.04 & 1.16 & 1.07 \\
\hline 202-N150-A0 & 147.72 & 111.11 & 0.75 & 3.70 & 3.76 & 3.48 & 3.32 & 3.27 & 3.71 & 3.48 & 1.08 & 1.13 & 1.08 & 1.15 & 1.01 \\
\hline 302-N100-A0 & 157.69 & 52.63 & 0.33 & 2.63 & 5.62 & 5.40 & 5.28 & 5.34 & 5.34 & 5.40 & 1.04 & 1.07 & 1.04 & 1.05 & 1.05 \\
\hline 302-N120-A0 & 157.13 & 63.16 & 0.40 & 2.63 & 6.02 & 5.47 & 5.43 & 5.49 & 5.58 & 5.47 & 1.10 & 1.11 & 1.10 & 1.10 & 1.08 \\
\hline 302-N150-A0 & 157.67 & 78.95 & 0.50 & 2.63 & 6.64 & 5.59 & 5.71 & 5.76 & 6.12 & 5.59 & 1.19 & 1.16 & 1.19 & 1.15 & 1.09 \\
\hline Mean, Pm & & & & & & & & & & & 1.04 & 1.14 & 1.04 & 1.17 & 1.09 \\
\hline \multicolumn{11}{|c|}{ Coefficient of variation } & 0.15 & 0.05 & 0.05 & 0.08 & 0.06 \\
\hline
\end{tabular}


Table 3 Web crippling strengths of duplex stainless steel sections predicted from finite element analysis: $a / h$ for centred circular web perforation

\begin{tabular}{|c|c|c|c|c|c|c|c|c|c|c|c|}
\hline \multirow{2}{*}{ Specimen } & \multirow{2}{*}{$\begin{array}{c}\text { Thickness } \\
t \\
(\mathrm{~mm})\end{array}$} & \multicolumn{5}{|c|}{ Unfastened FEA load per web, $P_{\mathrm{FEA}}$} & \multicolumn{5}{|c|}{ Fastened FEA load per web, $P_{\text {FEA }}$} \\
\hline & & $\begin{array}{l}A(0) \\
(k N)\end{array}$ & $\begin{array}{l}A(0.2) \\
(k N)\end{array}$ & $\begin{array}{l}A(0.4) \\
(k N)\end{array}$ & $\begin{array}{l}A(0.6) \\
(k N)\end{array}$ & $\begin{array}{l}A(0.8) \\
(k N)\end{array}$ & $\begin{array}{l}A(0) \\
(k N)\end{array}$ & $\begin{array}{l}A(0.2) \\
(k N)\end{array}$ & $\begin{array}{l}A(0.4) \\
(k N)\end{array}$ & $\begin{array}{l}A(0.6) \\
(k N)\end{array}$ & $\begin{array}{l}A(0.8) \\
(k N)\end{array}$ \\
\hline $142-\mathrm{N} 100$ & 1.27 & 3.34 & 3.01 & 2.62 & 2.27 & 2.01 & 5.57 & 5.16 & 4.66 & 4.13 & 2.98 \\
\hline $142-\mathrm{N} 100$ & 4.00 & 46.82 & 40.39 & 33.83 & 27.62 & 20.82 & 74.15 & 67.29 & 58.58 & 48.78 & 25.39 \\
\hline $142-\mathrm{N} 100$ & 6.00 & 114.74 & 99.47 & 83.03 & 51.75 & 40.15 & 169.62 & 154.59 & 133.85 & 106.70 & 46.40 \\
\hline $142-\mathrm{N} 120$ & 1.27 & 3.60 & 3.26 & 2.84 & 2.46 & 2.52 & 6.18 & 5.74 & 5.20 & 4.65 & 3.60 \\
\hline $142-\mathrm{N} 120$ & 4.00 & 51.20 & 44.74 & 37.81 & 31.30 & 24.73 & 84.10 & 77.00 & 67.97 & 58.16 & 33.89 \\
\hline $142-\mathrm{N} 120$ & 6.00 & 125.16 & 109.72 & 92.97 & 76.91 & 55.31 & 194.88 & 176.45 & 155.14 & 130.30 & 69.02 \\
\hline $142-\mathrm{N} 150$ & 1.28 & 4.02 & 3.66 & 3.18 & 2.78 & 2.40 & 7.11 & 6.66 & 6.08 & 5.46 & 4.64 \\
\hline $142-\mathrm{N} 150$ & 4.00 & 57.70 & 51.29 & 43.94 & 37.26 & 30.43 & 97.98 & 90.89 & 81.73 & 71.58 & 55.16 \\
\hline $142-\mathrm{N} 150$ & 6.00 & 140.18 & 124.51 & 106.81 & 91.07 & 73.48 & 227.83 & 208.56 & 186.57 & 162.23 & 116.43 \\
\hline 202-N100 & 1.39 & 3.04 & 2.75 & 2.33 & 2.01 & 1.82 & 5.27 & 4.84 & 4.29 & 3.52 & 2.93 \\
\hline 202-N100 & 4.00 & 37.72 & 31.90 & 26.13 & 22.25 & 19.60 & 62.08 & 55.33 & 46.59 & 36.25 & 25.35 \\
\hline 202-N100 & 6.00 & 96.81 & 81.88 & 64.30 & 53.00 & 40.75 & 151.34 & 132.80 & 111.58 & 79.65 & 47.52 \\
\hline 202-N120 & 1.39 & 3.23 & 2.92 & 2.48 & 2.05 & 1.86 & 5.72 & 5.28 & 4.69 & 3.63 & 3.02 \\
\hline 202-N120 & 4.00 & 40.61 & 34.56 & 28.34 & 22.71 & 19.95 & 69.47 & 62.50 & 52.26 & 37.39 & 26.13 \\
\hline 202-N120 & 6.00 & 105.25 & 89.91 & 70.91 & 54.34 & 41.67 & 169.64 & 149.80 & 127.15 & 82.16 & 48.80 \\
\hline 202-N150 & 1.39 & 3.48 & 3.17 & 2.72 & 2.28 & 1.90 & 6.41 & 5.96 & 5.33 & 4.64 & 3.14 \\
\hline 202-N150 & 4.00 & 45.22 & 39.37 & 31.99 & 25.88 & 20.46 & 80.39 & 70.52 & 63.51 & 52.42 & 27.24 \\
\hline $202-N 150$ & 6.00 & 117.65 & 102.26 & 82.37 & 64.36 & 42.96 & 196.97 & 176.28 & 151.83 & 123.27 & 50.82 \\
\hline $302-\mathrm{N} 100$ & 1.98 & 5.39 & 4.84 & 4.08 & 3.65 & 3.22 & 9.56 & 8.65 & 7.54 & 6.55 & 5.43 \\
\hline $302-\mathrm{N} 100$ & 4.00 & 30.04 & 27.10 & 21.89 & 19.76 & 17.51 & 48.94 & 43.60 & 37.03 & 31.95 & 24.49 \\
\hline $302-\mathrm{N} 100$ & 6.00 & 74.39 & 65.16 & 54.03 & 48.56 & 41.97 & 124.84 & 108.66 & 92.01 & 77.88 & 52.93 \\
\hline $302-N 120$ & 1.98 & 5.65 & 5.05 & 4.11 & 3.69 & 3.28 & 10.17 & 9.25 & 7.78 & 6.71 & 5.55 \\
\hline $302-\mathrm{N} 120$ & 4.00 & 31.77 & 27.10 & 22.14 & 19.99 & 17.72 & 53.45 & 47.87 & 38.59 & 32.72 & 24.99 \\
\hline $302-N 120$ & 6.00 & 83.43 & 69.47 & 55.29 & 49.37 & 42.81 & 139.05 & 121.14 & 96.43 & 79.90 & 54.08 \\
\hline $302-\mathrm{N} 150$ & 1.99 & 6.04 & 5.43 & 4.48 & 3.79 & 3.47 & 11.14 & 10.23 & 8.88 & 6.94 & 5.73 \\
\hline $302-\mathrm{N} 150$ & 4.00 & 34.26 & 29.30 & 23.89 & 20.43 & 18.14 & 60.53 & 54.77 & 45.38 & 33.87 & 25.73 \\
\hline $302-\mathrm{N} 150$ & 6.00 & 91.23 & 76.74 & 60.97 & 50.51 & 43.66 & 156.18 & 139.21 & 114.85 & 82.77 & 55.61 \\
\hline
\end{tabular}


Table 4 Web crippling strengths of duplex stainless steel sections predicted from finite element analysis: $a / h$ for offset circular web perforation

\begin{tabular}{|c|c|c|c|c|c|c|c|c|c|}
\hline \multirow[t]{2}{*}{ Specimen } & \multirow{2}{*}{$\begin{array}{c}\text { Thickness } \\
t \\
(\mathrm{~mm})\end{array}$} & \multicolumn{4}{|c|}{ Unfastened FEA load per web, $\mathrm{P}_{\mathrm{FEA}}$} & \multicolumn{4}{|c|}{ Fastened FEA load per web, $\mathrm{P}_{\mathrm{FEA}}$} \\
\hline & & $\begin{array}{l}A(0) \\
(k N)\end{array}$ & $\begin{array}{l}A(0.2) \\
(k N)\end{array}$ & $\begin{array}{l}A(0.4) \\
(k N)\end{array}$ & $\begin{array}{l}A(0.6) \\
(k N)\end{array}$ & $\begin{array}{l}A(0) \\
(k N)\end{array}$ & $\begin{array}{l}A(0.2) \\
(k N)\end{array}$ & $\begin{array}{l}A(0.4) \\
(k N)\end{array}$ & $\begin{array}{l}A(0.6) \\
(k N)\end{array}$ \\
\hline $142-\mathrm{N} 100$ & 1.27 & 3.34 & 3.31 & 3.27 & 3.25 & 5.58 & 5.57 & 5.56 & 5.55 \\
\hline $142-\mathrm{N} 100$ & 4.00 & 46.82 & 46.80 & 46.73 & 46.62 & 74.15 & 74.13 & 74.12 & 74.11 \\
\hline $142-\mathrm{N} 100$ & 6.00 & 114.74 & 114.69 & 114.58 & 114.37 & 171.90 & 171.89 & 171.88 & 171.85 \\
\hline $142-\mathrm{N} 120$ & 1.27 & 3.62 & 3.60 & 3.58 & 3.53 & 6.19 & 6.18 & 6.17 & 6.16 \\
\hline $142-\mathrm{N} 120$ & 4.00 & 51.21 & 51.18 & 51.11 & 50.99 & 84.10 & 84.08 & 84.07 & 84.05 \\
\hline $142-\mathrm{N} 120$ & 6.00 & 125.16 & 125.11 & 124.98 & 124.76 & 194.88 & 194.85 & 194.84 & 194.80 \\
\hline $142-\mathrm{N} 150$ & 1.28 & 4.03 & 4.02 & 3.99 & 3.95 & 7.12 & 7.11 & 7.10 & 7.09 \\
\hline $142-\mathrm{N} 150$ & 4.00 & 57.70 & 57.67 & 57.60 & 57.48 & 98.28 & 98.27 & 98.26 & 98.23 \\
\hline $142-\mathrm{N} 150$ & 6.00 & 140.18 & 140.13 & 139.99 & 139.77 & 227.83 & 227.81 & 227.80 & 227.76 \\
\hline 202-N100 & 1.39 & 3.05 & 3.04 & 2.98 & 2.89 & 5.27 & 5.26 & 5.24 & 5.18 \\
\hline 202-N100 & 4.00 & 37.72 & 37.69 & 37.63 & 37.50 & 62.08 & 62.06 & 62.05 & 62.03 \\
\hline 202-N100 & 6.00 & 96.81 & 96.76 & 96.68 & 96.51 & 151.35 & 151.31 & 151.29 & 151.26 \\
\hline 202-N120 & 1.39 & 3.23 & 3.22 & 3.17 & 3.07 & 5.72 & 5.71 & 5.69 & 5.64 \\
\hline 202-N120 & 4.00 & 40.61 & 40.58 & 40.52 & 40.40 & 69.47 & 69.45 & 69.43 & 69.42 \\
\hline 202-N120 & 6.00 & 105.25 & 105.19 & 104.93 & 104.93 & 169.64 & 169.63 & 169.60 & 169.56 \\
\hline 202-N150 & 1.39 & 3.49 & 3.47 & 3.41 & 3.30 & 6.43 & 6.41 & 6.38 & 6.33 \\
\hline 202-N150 & 4.00 & 45.23 & 45.18 & 45.09 & 44.62 & 80.39 & 80.36 & 80.35 & 80.32 \\
\hline 202-N150 & 6.00 & 117.65 & 117.57 & 117.42 & 117.13 & 196.97 & 196.93 & 196.91 & 196.85 \\
\hline $302-\mathrm{N} 100$ & 1.98 & 5.40 & 5.38 & 5.28 & 5.10 & 9.56 & 9.55 & 9.48 & 9.30 \\
\hline $302-\mathrm{N} 100$ & 2.00 & 30.04 & 29.99 & 29.82 & 29.44 & 48.96 & 48.93 & 48.91 & 48.85 \\
\hline $302-\mathrm{N} 100$ & 4.00 & 78.33 & 78.26 & 78.13 & 77.84 & 65.08 & 57.86 & 44.18 & 43.35 \\
\hline $302-\mathrm{N} 120$ & 1.98 & 5.66 & 5.63 & 5.28 & 5.25 & 5.32 & 4.72 & 3.91 & 3.52 \\
\hline $302-\mathrm{N} 120$ & 2.00 & 31.77 & 31.73 & 31.62 & 31.35 & 28.89 & 24.42 & 20.10 & 18.27 \\
\hline $302-\mathrm{N} 120$ & 4.00 & 83.43 & 82.34 & 82.20 & 81.90 & 75.69 & 62.55 & 49.29 & 44.31 \\
\hline $302-\mathrm{N} 150$ & 1.99 & 6.04 & 6.02 & 5.93 & 5.75 & 11.14 & 11.12 & 11.07 & 10.98 \\
\hline $302-\mathrm{N} 150$ & 2.00 & 34.27 & 34.22 & 34.12 & 33.88 & 31.02 & 26.31 & 21.63 & 18.63 \\
\hline $302-N 150$ & 4.00 & 91.23 & 91.14 & 91.03 & 90.80 & 82.88 & 69.35 & 53.65 & 45.33 \\
\hline
\end{tabular}


Table 5 Web crippling strengths of duplex stainless steel sections predicted from finite element analysis: $x / h$ for offset circular web perforation

\begin{tabular}{|c|c|c|c|c|c|c|c|c|c|}
\hline \multirow[t]{2}{*}{ Specimen } & \multirow{2}{*}{$\begin{array}{c}\text { Thickness } \\
t \\
(\mathrm{~mm}) \\
\end{array}$} & \multicolumn{4}{|c|}{ Unfastened FEA load per web, $P(F E A)$} & \multicolumn{4}{|c|}{ Fastened FEA load per web, $\mathrm{P}_{\mathrm{FEA}}$} \\
\hline & & $\begin{array}{l}X(0) \\
(k N)\end{array}$ & $\begin{array}{c}X(0.2) \\
(k N)\end{array}$ & $\begin{array}{c}X(0.4) \\
(k N)\end{array}$ & $\begin{array}{c}X(0.6) \\
(k N)\end{array}$ & $\begin{array}{l}X(0) \\
(k N)\end{array}$ & $\begin{array}{c}X(0.2) \\
(k N)\end{array}$ & $\begin{array}{c}X(0.4) \\
(k N)\end{array}$ & $\begin{array}{c}X(0.6) \\
(k N)\end{array}$ \\
\hline $142-\mathrm{N} 100-\mathrm{A} 0$ & 1.27 & 3.34 & 3.34 & 3.34 & 3.34 & 5.58 & 5.58 & 5.58 & 5.58 \\
\hline $142-\mathrm{N} 100-\mathrm{A} 0.2$ & 1.27 & 3.15 & 3.18 & 3.22 & 3.24 & 5.39 & 5.43 & 5.47 & 5.51 \\
\hline $142-\mathrm{N} 100-\mathrm{A} 0.4$ & 1.27 & 2.86 & 2.96 & 3.03 & 3.09 & 5.12 & 5.21 & 5.30 & 5.38 \\
\hline $142-\mathrm{N} 100-\mathrm{A} 0.6$ & 1.27 & 2.59 & 2.72 & 2.83 & 2.93 & 4.87 & 5.01 & 5.13 & 5.24 \\
\hline $142-\mathrm{N} 120-\mathrm{A} 0$ & 1.27 & 3.61 & 3.61 & 3.61 & 3.61 & 6.18 & 6.18 & 6.18 & 6.18 \\
\hline $142-\mathrm{N} 120-\mathrm{A} 0.2$ & 1.27 & 3.43 & 3.47 & 3.49 & 3.52 & 6.01 & 6.04 & 6.08 & 6.12 \\
\hline 142-N120-A0.4 & 1.27 & 3.16 & 3.24 & 3.31 & 3.37 & 5.75 & 5.84 & 5.92 & 6.00 \\
\hline 142-N120-A0.6 & 1.27 & 2.91 & 3.03 & 3.12 & 3.22 & 5.54 & 5.68 & 5.79 & 5.89 \\
\hline $142-\mathrm{N} 150-\mathrm{A} 0$ & 1.28 & 4.03 & 4.03 & 4.03 & 4.03 & 7.11 & 7.11 & 7.11 & 7.11 \\
\hline $142-\mathrm{N} 150-\mathrm{A} 0.2$ & 1.28 & 3.87 & 3.89 & 3.92 & 3.94 & 6.95 & 6.98 & 7.02 & 7.05 \\
\hline 142-N150-A0.4 & 1.28 & 3.62 & 3.67 & 3.75 & 3.81 & 6.70 & 6.79 & 6.87 & 6.95 \\
\hline 142-N150-A0.6 & 1.28 & 3.40 & 3.50 & 3.59 & 3.68 & 6.49 & 6.64 & 6.75 & 6.85 \\
\hline 202-N100-A0 & 1.39 & 3.05 & 3.05 & 3.05 & 3.05 & 5.27 & 5.27 & 5.27 & 5.27 \\
\hline 202-N100-A0.2 & 1.39 & 2.86 & 2.90 & 2.92 & 2.95 & 5.04 & 5.07 & 5.11 & 5.14 \\
\hline 202-N100-A0.4 & 1.39 & 2.56 & 2.66 & 2.72 & 2.78 & 4.71 & 4.79 & 4.87 & 4.94 \\
\hline 202-N100-A0.6 & 1.39 & 2.26 & 2.39 & 2.48 & 2.53 & 4.36 & 4.47 & 4.57 & 4.66 \\
\hline 202-N120-A0 & 1.39 & 3.23 & 3.23 & 3.23 & 3.23 & 5.72 & 5.72 & 5.72 & 5.72 \\
\hline 202-N120-A0.2 & 1.39 & 3.05 & 3.09 & 3.11 & 3.13 & 5.50 & 5.53 & 5.56 & 5.60 \\
\hline 202-N120-A0.4 & 1.39 & 2.75 & 2.85 & 2.91 & 2.97 & 5.18 & 5.25 & 5.33 & 5.40 \\
\hline 202-N120-A0.6 & 1.39 & 2.46 & 2.58 & 2.68 & 2.77 & 4.88 & 4.99 & 5.08 & 5.17 \\
\hline 202-N150-A0 & 1.45 & 3.49 & 3.49 & 3.49 & 3.49 & 6.41 & 6.41 & 6.41 & 6.41 \\
\hline 202-N150-A0.2 & 1.45 & 3.32 & 3.35 & 3.37 & 3.39 & 6.21 & 6.23 & 6.27 & 6.30 \\
\hline 202-N150-A0.4 & 1.45 & 3.04 & 3.11 & 3.18 & 3.24 & 5.90 & 5.97 & 6.05 & 6.15 \\
\hline 202-N150-A0.6 & 1.45 & 2.75 & 2.86 & 2.96 & 3.05 & 5.64 & 5.75 & 5.84 & 5.92 \\
\hline $302-\mathrm{N} 100-\mathrm{A} 0$ & 1.98 & 5.40 & 5.40 & 5.40 & 5.40 & 9.56 & 9.56 & 9.56 & 9.56 \\
\hline $302-\mathrm{N} 100-\mathrm{A} 0.2$ & 1.98 & 5.03 & 5.09 & 5.15 & 5.22 & 8.99 & 9.07 & 9.12 & 9.18 \\
\hline 302-N120-A0 & 1.96 & 5.66 & 5.66 & 5.66 & 5.66 & 10.00 & 10.00 & 10.00 & 10.00 \\
\hline $302-\mathrm{N} 120-\mathrm{A} 0.2$ & 1.96 & 5.27 & 5.33 & 5.40 & 5.47 & 9.64 & 9.70 & 9.75 & 9.81 \\
\hline $302-\mathrm{N} 120-\mathrm{A} 0.4$ & 1.96 & 4.83 & 4.87 & 5.00 & 5.15 & 9.11 & 9.19 & 9.24 & 9.36 \\
\hline $302-\mathrm{N} 150-\mathrm{A} 0$ & 1.99 & 6.04 & 6.04 & 6.04 & 6.04 & 11.14 & 11.14 & 11.14 & 11.14 \\
\hline $302-\mathrm{N} 150-\mathrm{A} 0.2$ & 1.99 & 5.67 & 5.73 & 5.80 & 5.87 & 10.68 & 10.74 & 10.80 & 10.84 \\
\hline $302-\mathrm{N} 150-\mathrm{A} 0.4$ & 1.99 & 5.07 & 5.24 & 5.40 & 5.55 & 10.04 & 10.19 & 10.31 & 10.42 \\
\hline
\end{tabular}


Table 6 Comparison of web crippling strength reduction factor for cold-formed stainless steel lipped channels with reduction factors equations proposed by Uzzaman et al. (2012c, 2013)

(a) Flanges unfastened to the bearing plates

\begin{tabular}{|c|c|c|c|c|c|c|c|c|c|c|c|c|c|c|c|}
\hline \multirow[t]{4}{*}{ Specimen } & \multirow{3}{*}{\multicolumn{2}{|c|}{$\begin{array}{l}\text { Factored resistance } \\
\qquad \text { (Eq. 1) }\end{array}$}} & \multirow{4}{*}{$\begin{array}{l}\text { Factored resistance } \\
\qquad \begin{array}{c}\text { (Eq. 3) } \\
\text { Offset }\end{array}\end{array}$} & \multicolumn{6}{|c|}{ Reduction factor } & \multicolumn{6}{|c|}{$\begin{array}{l}\text { Comparison with resistance from Uzzaman et al } \\
\qquad R / R_{\text {Uzzaman }}\end{array}$} \\
\hline & & & & \multirow{2}{*}{\multicolumn{2}{|c|}{$\begin{array}{c}\text { Duplex } \\
R=P(\text { Opening }) / P(A 0)\end{array}$}} & \multirow{2}{*}{\multicolumn{2}{|c|}{$\begin{array}{c}\text { Ferritic } \\
R=P(\text { Opening }) / P(A 0)\end{array}$}} & \multirow{2}{*}{\multicolumn{2}{|c|}{$\begin{array}{c}\text { Austenitic } \\
R=P(\text { Opening }) / P(A 0)\end{array}$}} & \multirow{3}{*}{$\begin{array}{l}\text { Duplex } \\
\text { Centred }\end{array}$} & & \multirow{3}{*}{$\begin{array}{l}\text { Ferritic } \\
\text { Centred }\end{array}$} & \multirow{3}{*}{\multicolumn{2}{|c|}{$\begin{array}{ll} & \text { Austenitic } \\
& \\
\text { ffset } & \text { Centred }\end{array}$}} & \multirow[b]{3}{*}{ Offset } \\
\hline & & & & & & & & & & & & & & & \\
\hline & & Centred & & Centred & Offset & Centred & Offset & Centred & Offset & & Offset & & & & \\
\hline 142-N100-MA0.6-FR & & 0.63 & 0.92 & 0.68 & 0.92 & 0.68 & 0.99 & 0.69 & 0.98 & 1.09 & 1.08 & 1.08 & 1.07 & 1.09 & 1.06 \\
\hline 142-N120-MA0.6-FR & & 0.63 & 0.92 & 0.68 & 0.93 & 0.73 & 0.99 & 0.69 & 0.98 & 1.08 & 1.07 & 1.16 & 1.07 & 1.10 & 1.07 \\
\hline 142-N150-MA0.4-FR & & 0.75 & 1.03 & 0.79 & 0.96 & 0.78 & 0.99 & 0.79 & 0.99 & 1.05 & 0.96 & 1.04 & 0.96 & 1.05 & 0.96 \\
\hline 202-N100-MA0.4-FR & & 0.73 & 1.02 & 0.77 & 0.93 & 0.77 & 0.98 & 0.78 & 0.98 & 1.05 & 0.96 & 1.05 & 0.96 & 1.06 & 0.96 \\
\hline 202-N100-MA0.6-FR & & 0.63 & 0.90 & 0.66 & 0.98 & 0.72 & 0.95 & 0.69 & 0.95 & 1.05 & 1.05 & 1.14 & 1.05 & 1.10 & 1.05 \\
\hline 202-N120-MA0.4-FR & & 0.73 & 1.02 & 0.77 & 0.93 & 0.77 & 0.98 & 0.78 & 0.98 & 1.05 & 0.96 & 1.05 & 0.96 & 1.06 & 0.96 \\
\hline 202-N120-MA0.6-FR & & 0.63 & 0.91 & 0.64 & 0.88 & 0.69 & 0.95 & 0.66 & 0.96 & 1.01 & 1.06 & 1.09 & 1.05 & 1.05 & 1.06 \\
\hline 202-N150-MA0.4-FR & & 0.74 & 1.02 & 0.78 & 0.95 & 0.78 & 0.98 & 0.78 & 0.98 & 1.06 & 0.96 & 1.06 & 0.96 & 1.07 & 0.97 \\
\hline 302-N100-MA0.6-FR & & 0.58 & 0.96 & 0.68 & 0.98 & 0.69 & 0.94 & 0.66 & 0.94 & 1.17 & 0.98 & 1.19 & 0.98 & 1.15 & 0.97 \\
\hline 302-N120-MA0.4-FR & & 0.58 & 0.97 & 0.65 & 0.95 & 0.62 & 0.96 & 0.64 & 0.94 & 1.12 & 0.95 & 1.07 & 0.99 & 1.10 & 0.97 \\
\hline 302-N150-MA0.4-FR & & 0.58 & 0.99 & 0.63 & 0.99 & 0.67 & 0.95 & 0.61 & 0.96 & 1.08 & 0.96 & 1.15 & 0.96 & 1.05 & 0.96 \\
\hline Mean, Pm & $\#$ & \# & $\#$ & \# & \# & \# & \# & & & $1.07 \#$ & 1.00 & 1.10 & 1.00 & 1.08 & 1.00 \\
\hline Coefficient of & & \# & & \# & \# & \# & \# & & & & & & & & \\
\hline variation, $\mathrm{Vp}$ & $\#$ & & \# & & & & & & & $0.04 \#$ & 0.06 & 0.05 & 0.05 & 0.03 & 0.05 \\
\hline
\end{tabular}


(b) Flanges fastened to the bearing plates

\begin{tabular}{|c|c|c|c|c|c|c|c|c|c|c|c|c|c|c|}
\hline \multirow[t]{4}{*}{ Specimen } & \multirow[t]{3}{*}{$\begin{array}{c}\text { Factored resistance } \\
\text { (Eq. 2) }\end{array}$} & \multirow[t]{3}{*}{$\begin{array}{l}\text { Factored resistance } \\
\quad \text { (Eq. 4) }\end{array}$} & \multicolumn{5}{|c|}{ Reduction factor } & & \multicolumn{6}{|c|}{$\begin{array}{l}\text { Comparison with resistance from Uzzaman et al } \\
\qquad R / R_{\text {Uzzaman }}\end{array}$} \\
\hline & & & \multirow{2}{*}{\multicolumn{2}{|c|}{$\begin{array}{c}\text { Duplex } \\
R=P(\text { Hole }) / P(A 0)\end{array}$}} & \multirow{2}{*}{$\begin{array}{c}\text { Ferritic } \\
R=P(\text { Hole }) / P(A 0)\end{array}$} & \multirow{2}{*}{\multicolumn{3}{|c|}{$\begin{array}{c}\text { Austenitic } \\
R=P(\text { Hole }) / P(A 0)\end{array}$}} & \multirow{3}{*}{$\begin{array}{l}\text { Duplex } \\
\text { Centred }\end{array}$} & \multirow{3}{*}{\multicolumn{2}{|c|}{$\begin{array}{ll} & \text { Ferritic } \\
& \\
\text { ffset } & \text { Centred }\end{array}$}} & \multirow[b]{3}{*}{ Offset } & \multirow{3}{*}{$\begin{array}{c}\text { Austenitic } \\
\text { Centred }\end{array}$} & \multirow[b]{3}{*}{ Offse } \\
\hline & & & & & & & & & & & & & & \\
\hline & Centred & Offset & Centred & Offset & Centred & Offset & Centred & Offset & & & & & & \\
\hline 142-N100-MA0.6-FX & 0.71 & 0.96 & 0.74 & 1.00 & 0.75 & 0.99 & 0.75 & 0.98 & 1.05 & 1.03 & 1.06 & 1.03 & 1.07 & 1.02 \\
\hline 142-N120-MA0.6-FX & 0.71 & 0.96 & 0.75 & 0.99 & 0.64 & 0.99 & 0.76 & 0.99 & 1.06 & 1.03 & 0.90 & 1.03 & 1.07 & 1.02 \\
\hline 142-N150-MA0.4-FX & 0.81 & 1.05 & 0.86 & 1.00 & 0.59 & 0.99 & 0.86 & 0.99 & 1.05 & 0.95 & 0.73 & 0.95 & 1.07 & 0.95 \\
\hline 202-N100-MA0.4-FX & 0.80 & 1.03 & 0.81 & 1.00 & 0.82 & 0.99 & 0.78 & 1.00 & 1.02 & 0.97 & 1.03 & 0.96 & 0.97 & 0.96 \\
\hline 202-N100-MA0.6-FX & 0.71 & 0.95 & 0.67 & 0.98 & 0.77 & 0.99 & 0.69 & 0.99 & 0.94 & 1.03 & 1.08 & 1.05 & 0.97 & 1.04 \\
\hline 202-N120-MA0.4-FX & 0.80 & 1.04 & 0.82 & 1.00 & 0.82 & 1.00 & 0.78 & 1.00 & 1.03 & 0.97 & 1.03 & 0.97 & 0.98 & 0.96 \\
\hline 202-N120-MA0.6-FX & 0.71 & 0.95 & 0.64 & 0.99 & 0.66 & 0.99 & 0.66 & 0.99 & 0.90 & 1.04 & 0.93 & 1.04 & 0.93 & 1.04 \\
\hline 202-N150-MA0.4-FX & 0.80 & 1.03 & 0.83 & 0.99 & 0.84 & 0.99 & 0.78 & 0.96 & 1.04 & 0.96 & 1.05 & 0.96 & 0.98 & 0.93 \\
\hline 302-N100-MA0.6-FX & 0.68 & 1.00 & 0.68 & 0.97 & 0.72 & 0.98 & 0.66 & 0.98 & 1.01 & 0.98 & 1.06 & 0.98 & 0.98 & 0.98 \\
\hline 302-N120-MA0.4-FX & 0.78 & 1.01 & 0.76 & 0.98 & 0.79 & 0.98 & 0.78 & 0.99 & 0.98 & 0.66 & 1.01 & 0.99 & 1.00 & 0.98 \\
\hline 302-N150-MA0.4-FX & 0.79 & 1.03 & 0.80 & 0.99 & 0.81 & 0.99 & 0.80 & 1.00 & 1.01 & 0.97 & 1.02 & 1.00 & 1.01 & 0.97 \\
\hline Mean, Pm & $\#$ & $\#$ & $\#$ & \# & \# & $\#$ & $\#$ & & 1.01 & 1.00 & 1.00 & 1.01 & 1.00 & 1.01 \\
\hline Coefficient of & & $\#$ & \# & \# & \# & \# & $\#$ & & & & & & & \\
\hline variation, $\mathrm{Vp}$ & $\#$ & & & & & & & & 0.05 & 0.04 & 0.10 & 0.04 & 0.05 & 0.04 \\
\hline
\end{tabular}


Table 7 Coefficients of the proposed strength reduction factor equations

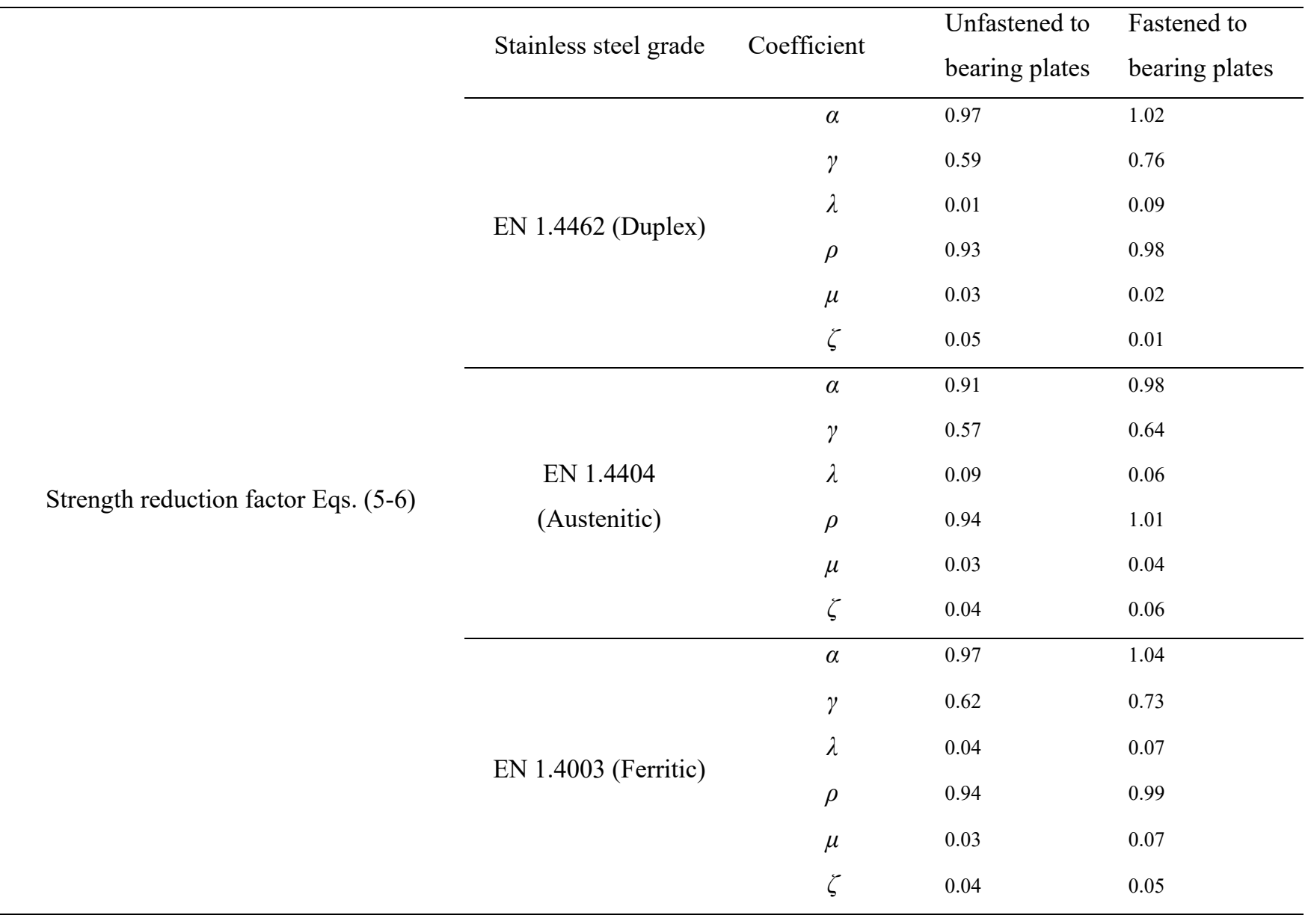


Table 8 Statistical analysis of strength reduction factor for three stainless steel grades

\begin{tabular}{|c|c|c|c|c|c|}
\hline \multirow[b]{2}{*}{ Stainless steel grade } & \multirow[b]{2}{*}{ Statistical parameters } & \multicolumn{2}{|c|}{$\begin{array}{c}\text { Centred circular web opening } \\
R_{(F E A)} / R_{p} \\
\end{array}$} & \multicolumn{2}{|c|}{$\begin{array}{c}\text { Offset circular web opening } \\
R_{(F E A)} / R_{p} \\
\end{array}$} \\
\hline & & $\begin{array}{c}\text { Unfastened } \\
\text { to bearing } \\
\text { plates }\end{array}$ & $\begin{array}{l}\text { Fastened } \\
\text { to bearing } \\
\text { plates }\end{array}$ & $\begin{array}{c}\text { Unfastened } \\
\text { to bearing } \\
\text { plates }\end{array}$ & $\begin{array}{l}\text { Fastened } \\
\text { to bearing } \\
\text { plates }\end{array}$ \\
\hline \multirow{5}{*}{$\begin{array}{l}\text { EN } 1.4462 \\
\text { (Duplex) }\end{array}$} & Number of data & 108 & 108 & 81 & 81 \\
\hline & Mean, $P_{m}$ & 1.00 & 1.00 & 1.00 & 1.00 \\
\hline & $\begin{array}{l}\text { Coefficient of } \\
\text { variation, } V_{p}\end{array}$ & 0.10 & 0.13 & 0.02 & 0.01 \\
\hline & Reliability index, $\beta$ & 2.62 & 2.51 & 2.84 & 2.85 \\
\hline & Resistance factor, $\phi$ & 0.85 & 0.85 & 0.85 & 0.85 \\
\hline \multirow{5}{*}{$\begin{array}{l}\text { EN } 1.4404 \\
\text { (Austenitic) }\end{array}$} & Number of data & 105 & 105 & 81 & 81 \\
\hline & Mean, $P_{m}$ & 1.00 & 1.00 & 1.00 & 1.00 \\
\hline & $\begin{array}{l}\text { Coefficient of } \\
\text { variation, } V_{p}\end{array}$ & 0.09 & 0.11 & 0.02 & 0.02 \\
\hline & Reliability index, $\beta$ & 2.66 & 2.54 & 2.84 & 2.84 \\
\hline & Resistance factor, $\phi$ & 0.85 & 0.85 & 0.85 & 0.85 \\
\hline \multirow{5}{*}{$\begin{array}{l}\text { EN } 1.4003 \\
\text { (Ferritic) }\end{array}$} & Number of data & 108 & 108 & 81 & 81 \\
\hline & Mean, $P_{m}$ & 1.00 & 1.00 & 1.00 & 1.00 \\
\hline & $\begin{array}{l}\text { Coefficient of } \\
\text { variation, } V_{p}\end{array}$ & 0.12 & 0.12 & 0.01 & 0.01 \\
\hline & Reliability index, $\beta$ & 2.54 & 2.52 & 2.85 & 2.85 \\
\hline & Resistance factor, $\phi$ & 0.85 & 0.85 & 0.85 & 0.85 \\
\hline
\end{tabular}




\section{Figure Captions}

Fig. 1. Photograph of cold-formed stainless steel lipped channel-sections with circular web openings after Lawson et. al. (2015)

Fig. 2. End-two-flange (ETF) loading condition after Uzzaman et al. (2012b, 2013)

(a) With circular web opening centred from bearing plates

(b) With circular web openings offset from bearing plates

Fig. 3. Experimental analysis of cold-formed steel lipped channel-sections under end-two-flange (ETF) loading condition for the case of flanges unfastened and fastened to bearing plates after Uzzaman et al. (2012b, 2013);

(a) Centred circular web opening

(b) Offset circular web opening

Fig. 4. Definition of symbols

Fig. 5. Deformed shape predicted from finite element analysis of cold-formed steel lipped channels under endtwo-flange (ETF) loading condition for case of flanges unfastened and fastened to bearing plates;

(a) Centred circular web perforation

(b) Offset circular web perforation

Fig. 6. Comparison of finite element results and experimental results by Uzzaman et al. (2012b) for sections with centred circular web opening

(a) For the case of flanges unfastened to bearing plates

(b) For the case of flanges fastened to bearing plates

Fig. 7. Comparison of finite element results and experimental results by Uzzaman et al. (2013) for sections with offset circular web opening

(a) For the case of flanges unfastened to bearing plates

(b) For the case of flanges fastened to bearing plates

Fig. 8. Variation in reduction factors for $\mathrm{C} 142$ section for the case of flanges unfastened to bearing plates

(a) with $a / h$ for centered circular web perforation

(b) with $N / h$ for centered circular web perforation

(c) with $x / h$ for offset circular web perforation

Fig. 9. Comparison of strength reduction factor for $\mathrm{C} 142$ section with centered circular web perforation

(a) For the case of flanges unfastened to bearing plates

(b) For the case of flanges fastened to bearing plates

Fig. 10. Comparison of strength reduction factor for $\mathrm{C} 142$ section with offset circular web perforation 
(a) For the case of flanges unfastened to bearing plates

(b) For the case of flanges fastened to bearing plates

Fig. 11 Comparison of strength reduction factor for sections with centered circular web perforation

(a) For the case of flanges unfastened to bearing plates

(b) For the case of flanges fastened to bearing plates

Fig. 12. Comparison of strength reduction factor for sections with offset circular web perforation

(a) For the case of flanges unfastened to bearing plates

(b) For the case of flanges fastened to bearing plates 


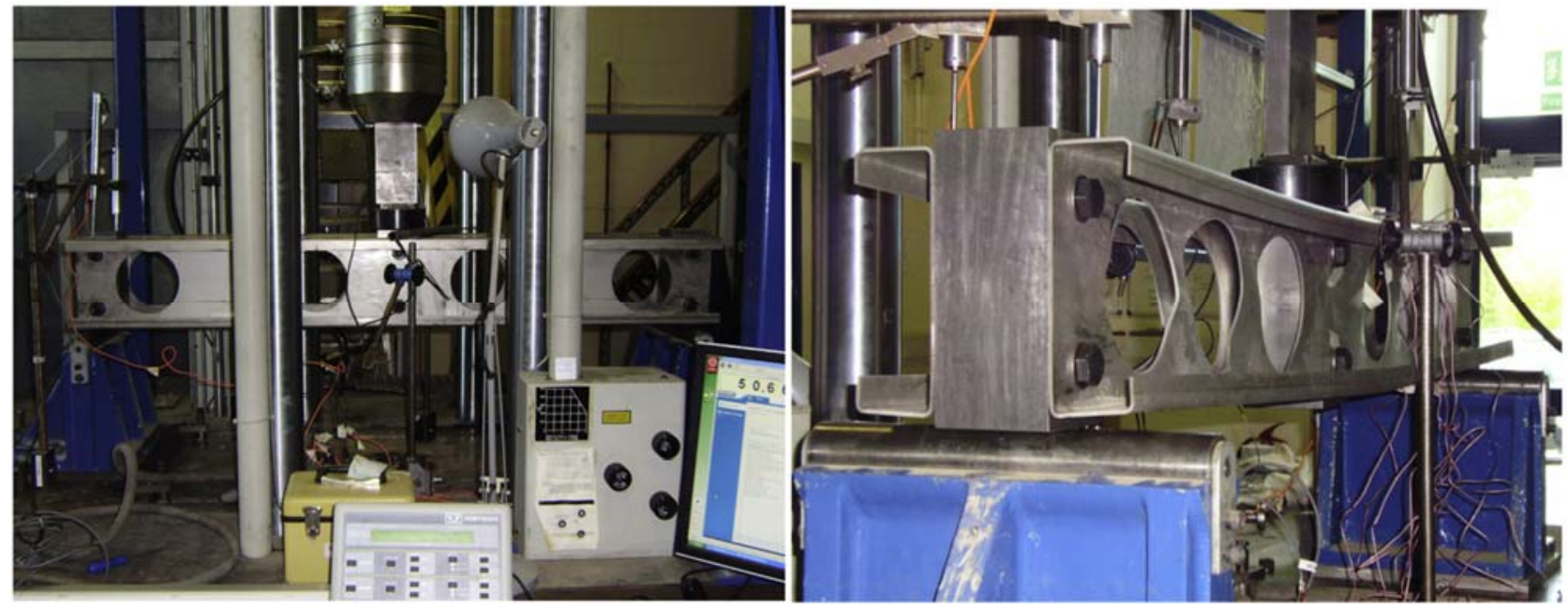

Fig. 1 Photograph of cold-formed stainless steel lipped channel-sections with circular web openings after Lawson et. al. (2015) 


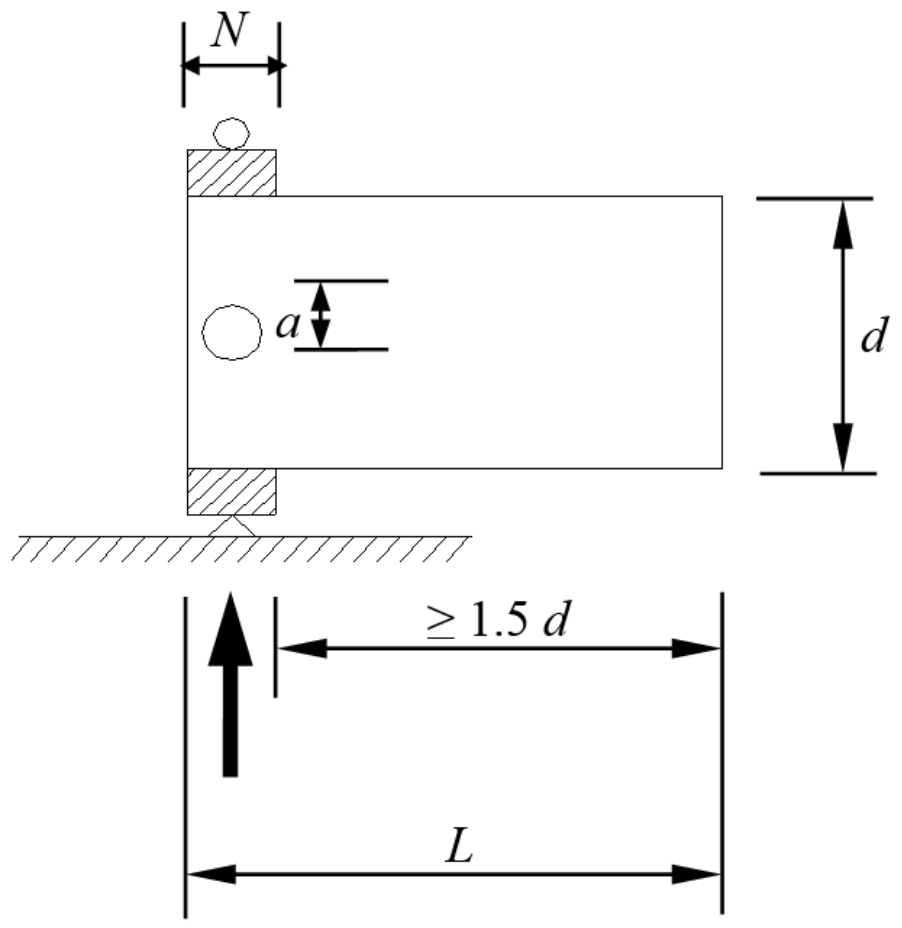

(a) With circular web opening centred from bearing plates

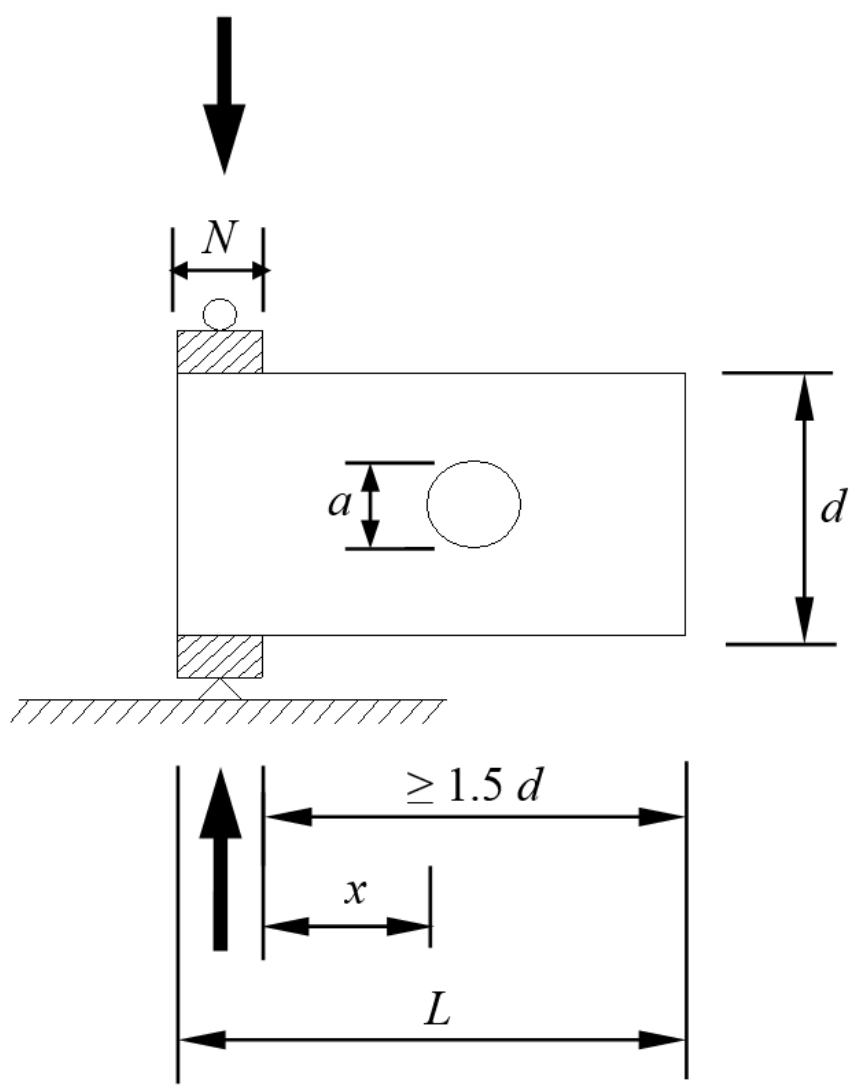

(b) With circular web openings offset from bearing plates

Fig. 2. End-two-flange (ETF) loading condition after Uzzaman et al. (2012b, 2013) 

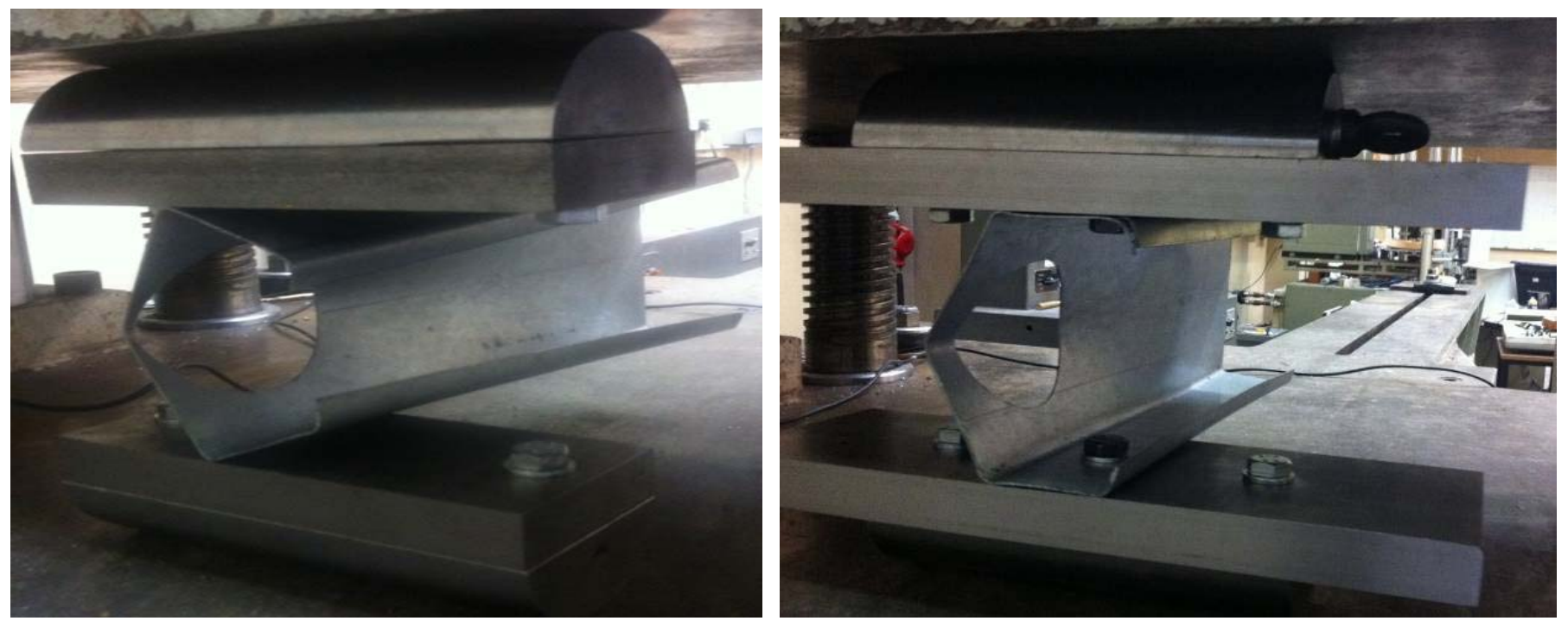

(a) Centred circular web opening
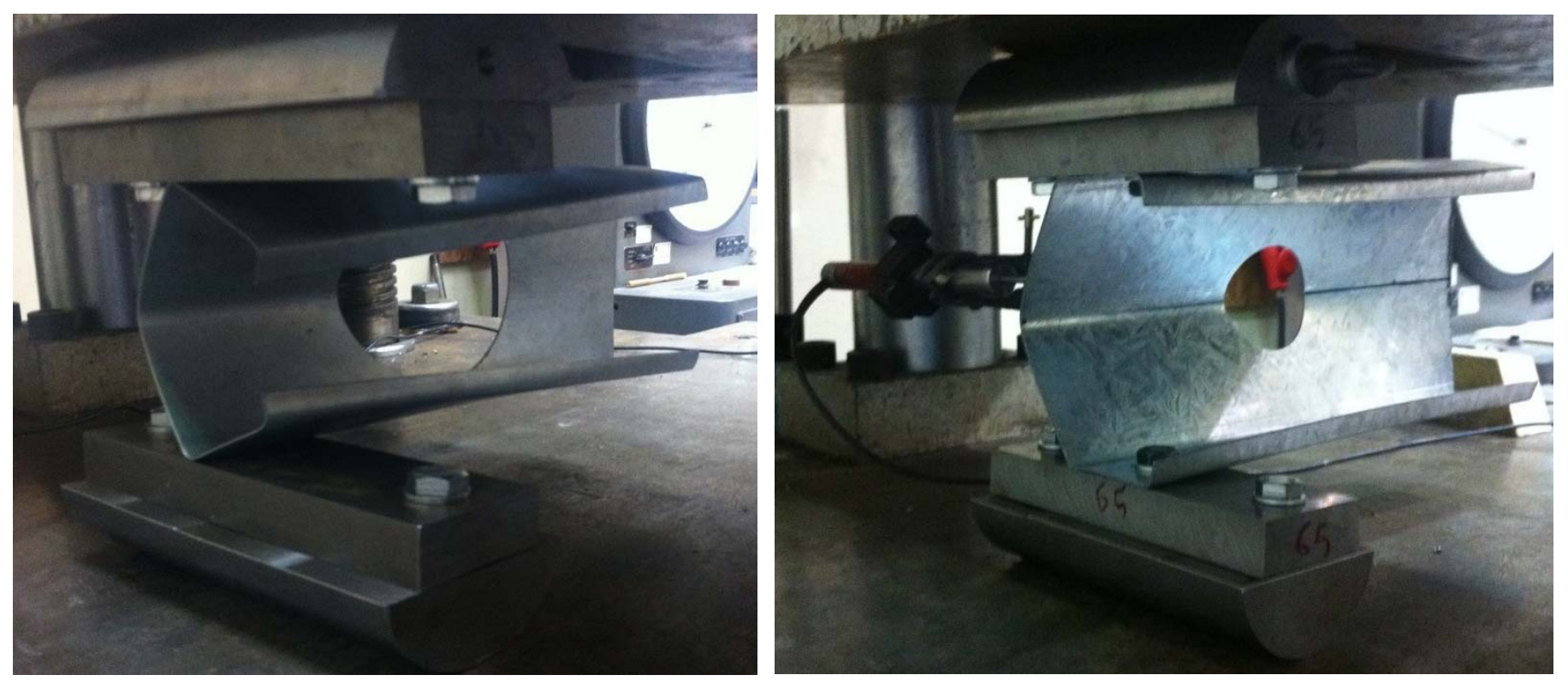

(b) Offset circular web opening

Fig. 3. Experimental analysis of cold-formed steel lipped channel-sections under end-two-flange (ETF) loading condition for the case of flanges unfastened and fastened to bearing plates after Uzzaman et al. (2012b, 2013) 


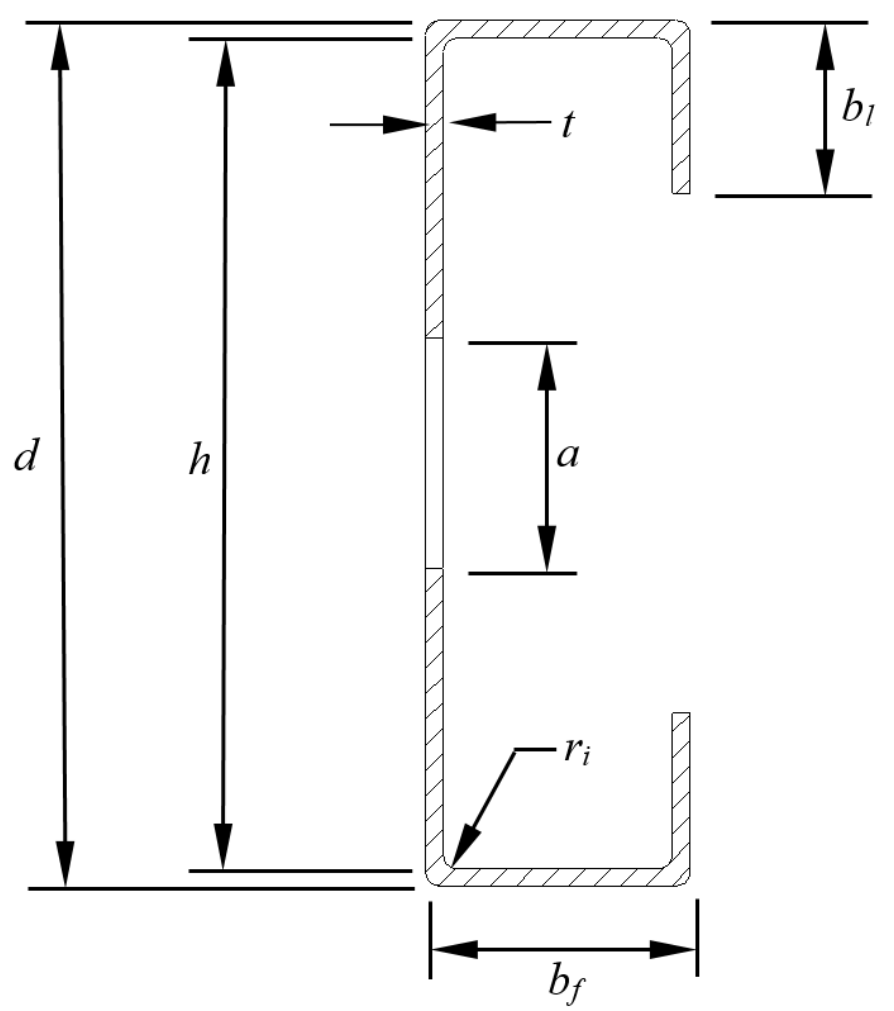

Fig. 4. Definition of symbols 


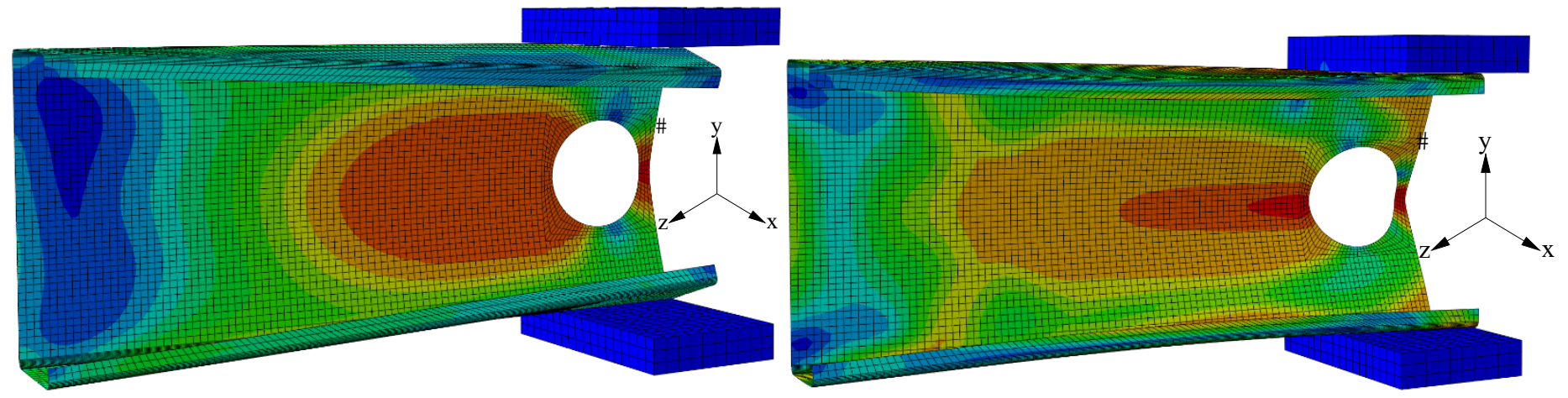

(a) Centred circular web perforation

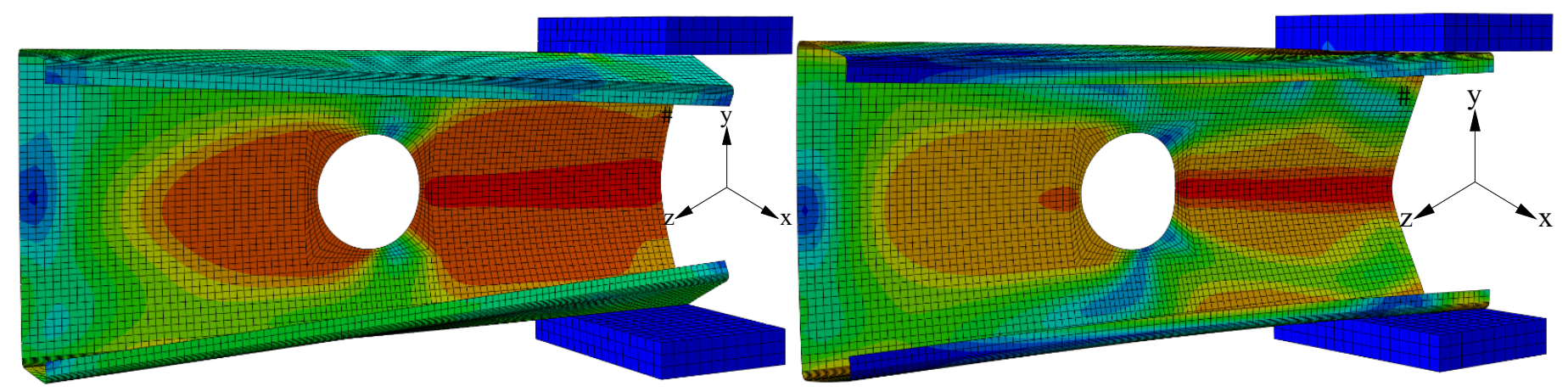

(b) Offset circular web perforation

Fig. 5. Deformed shape predicted from finite element analysis of cold-formed steel lipped channels under end-two-flange (ETF) loading condition for case of flanges unfastened and fastened to bearing plates 


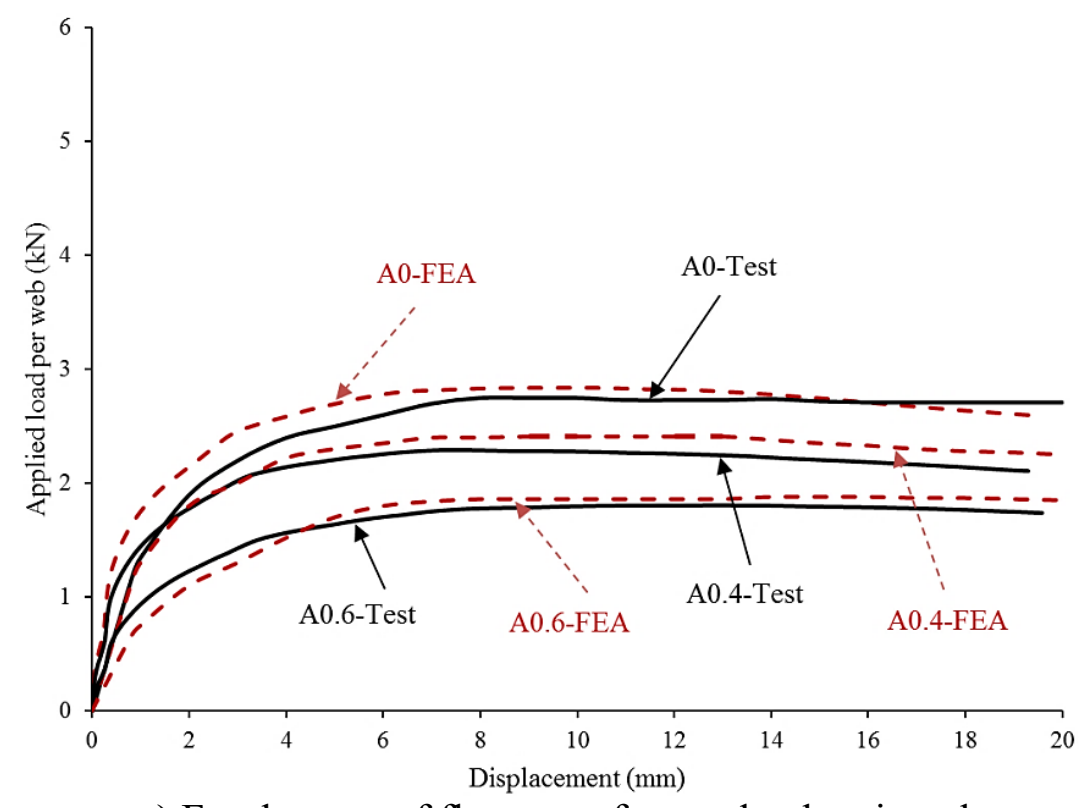

a) For the case of flanges unfastened to bearing plates

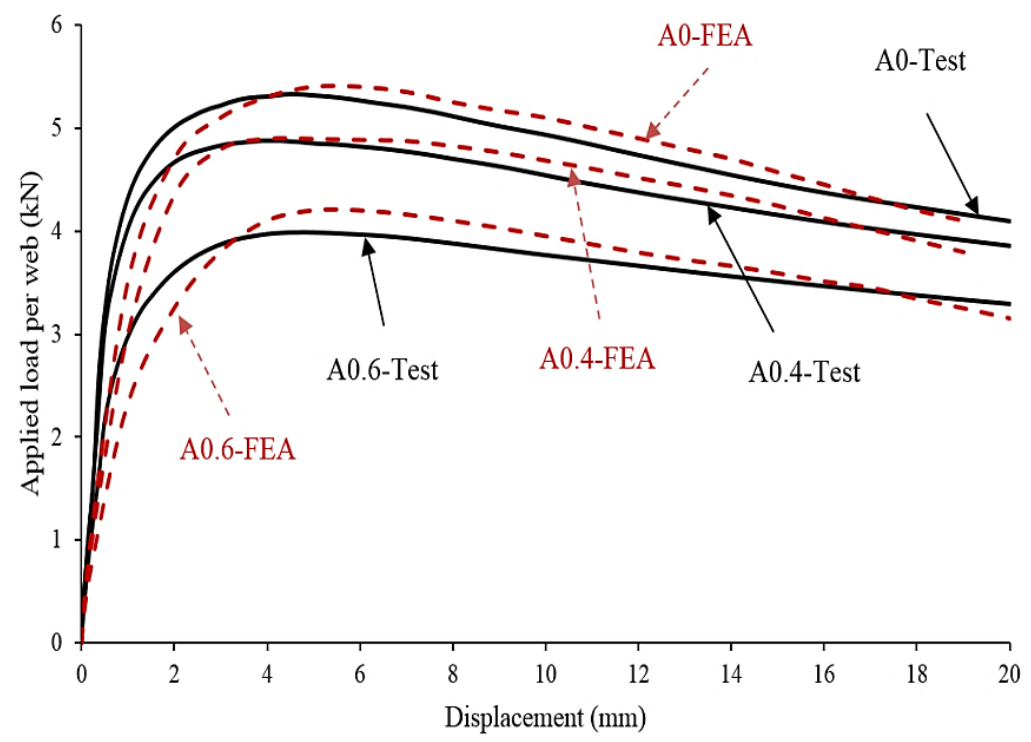

b) For the case of flanges fastened to bearing plates

Fig. 6. Comparison of finite element results and experimental results by Uzzaman et al. (2012b) for sections with centred circular web opening 


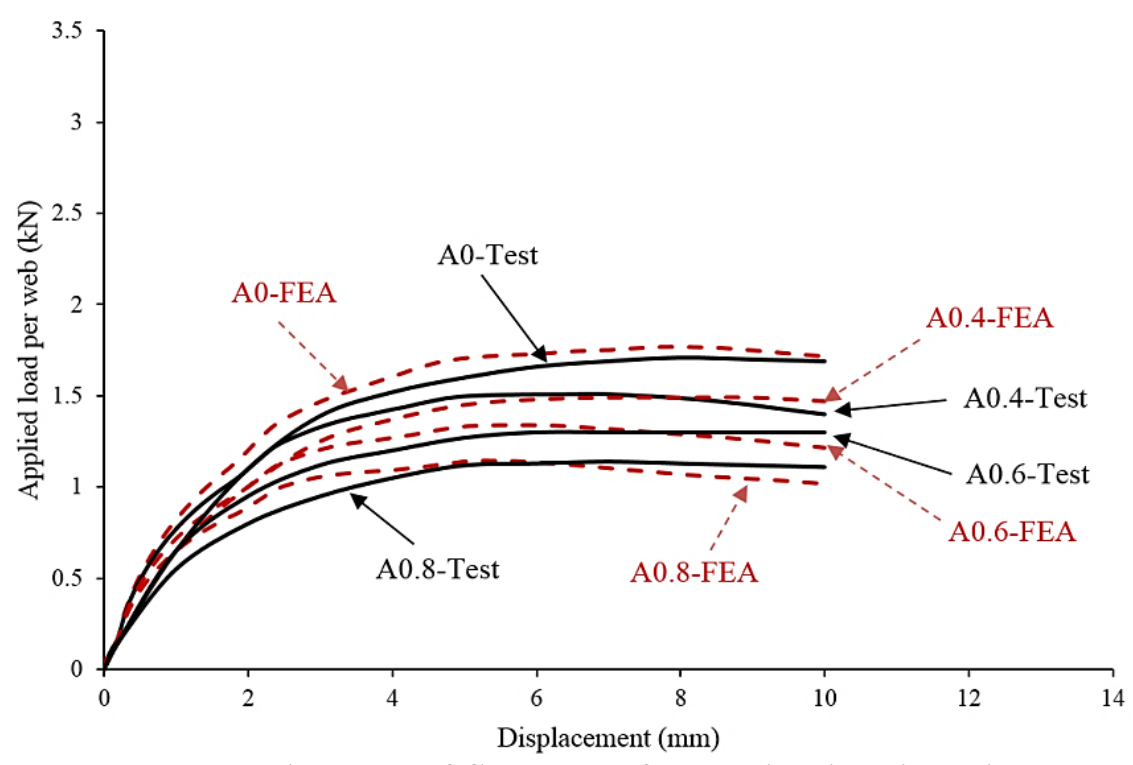

a) For the case of flanges unfastened to bearing plates

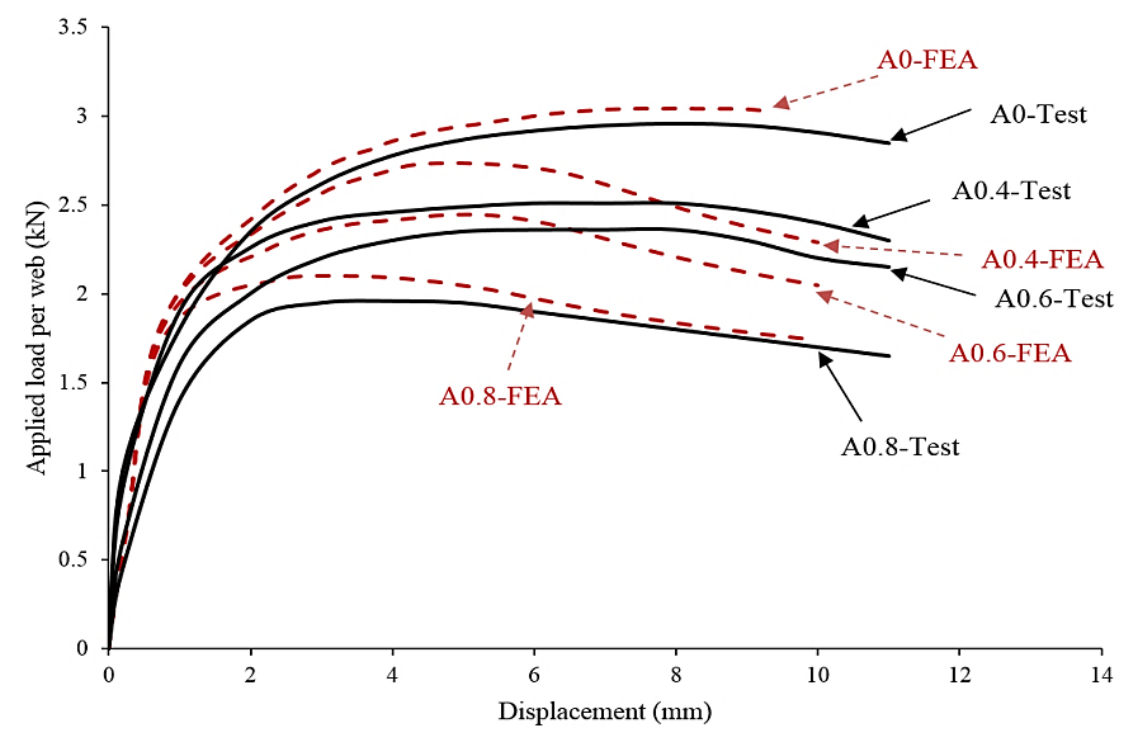

b) For the case of flanges fastened to bearing plates

Fig. 7. Comparison of finite element results and experimental results by Uzzaman et al. (2013) for sections with offset circular web opening 


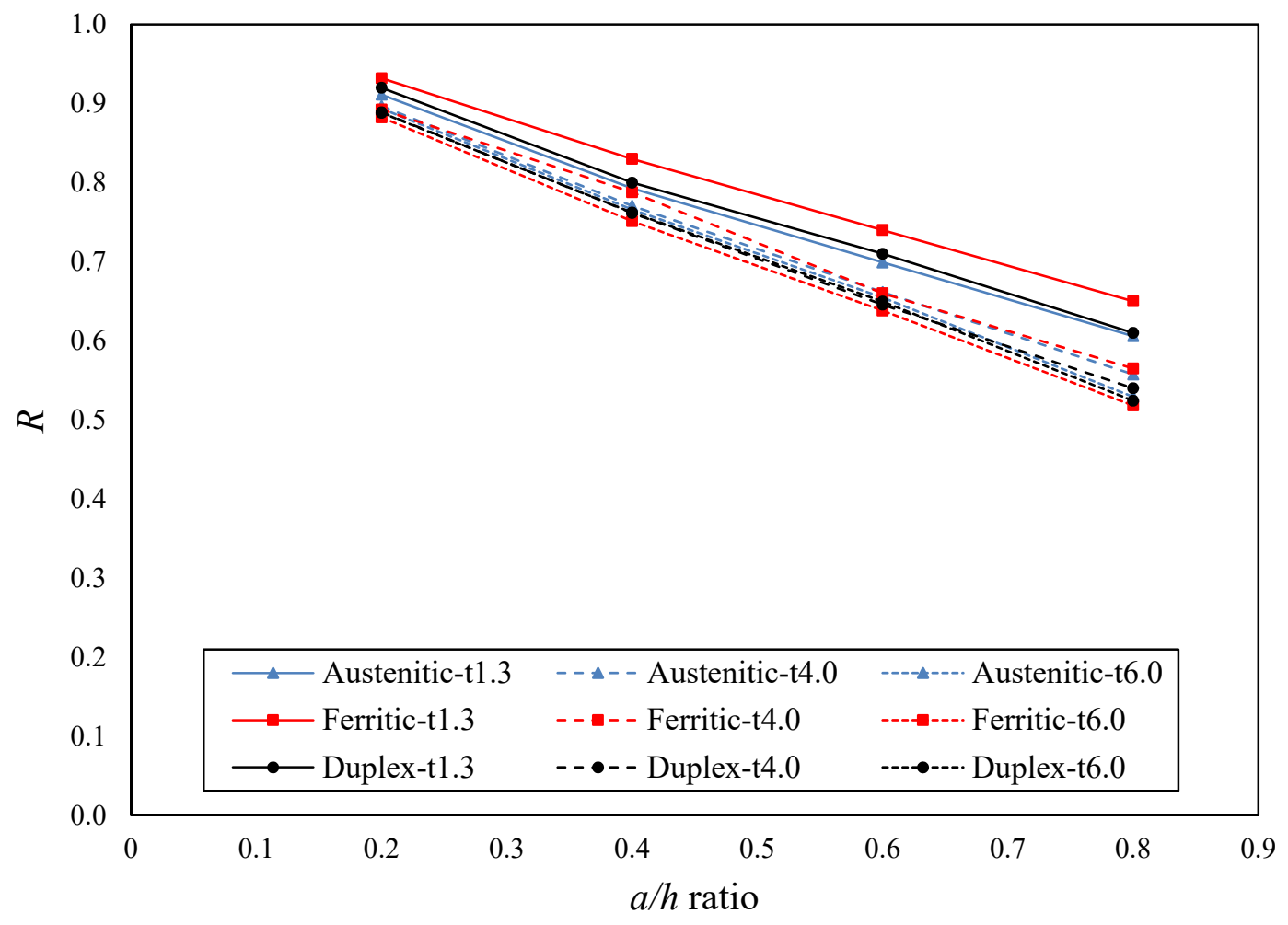

(a) with $a / h$ for centered circular web perforation 


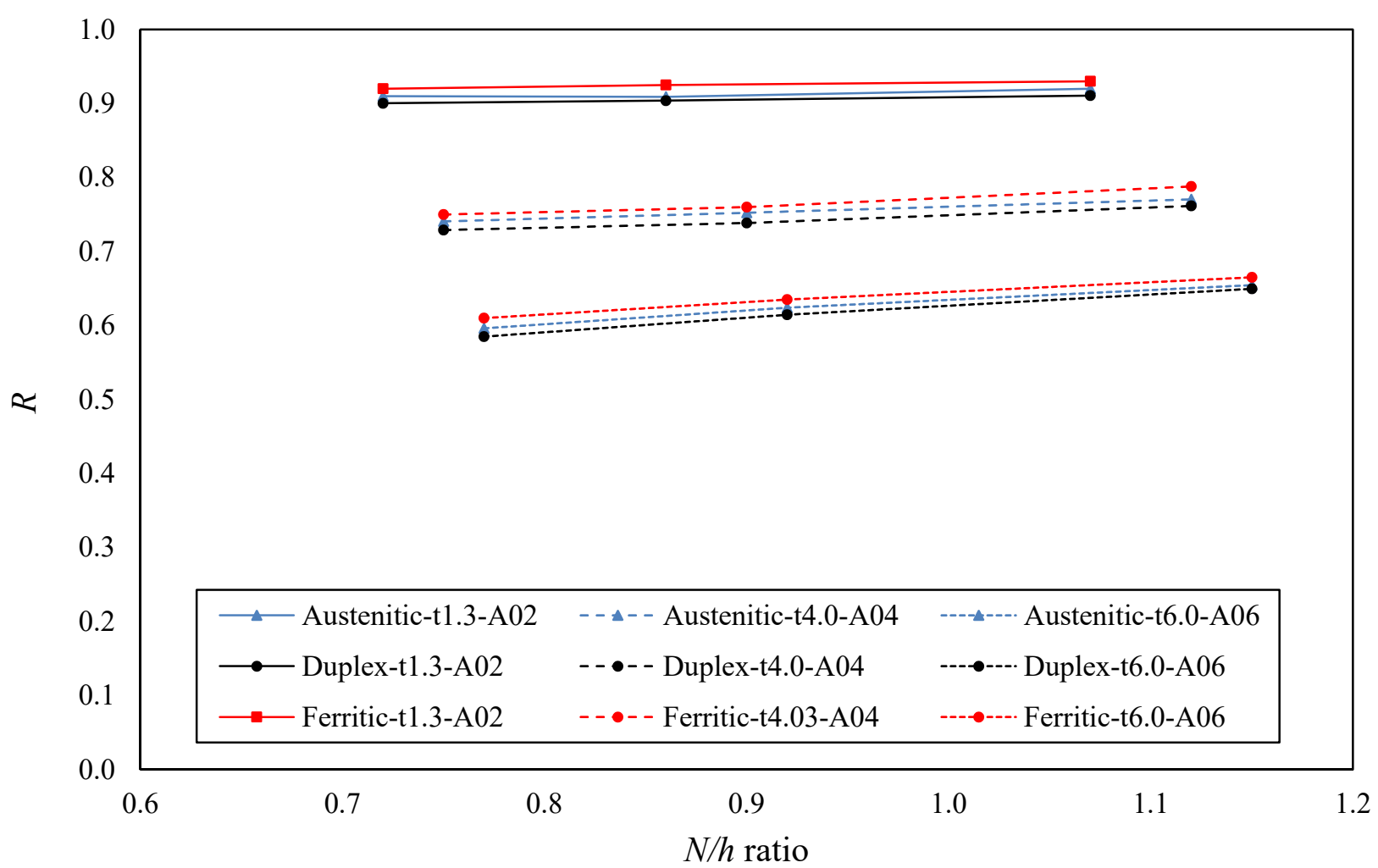

(b) with $N / h$ for centered circular web perforation 


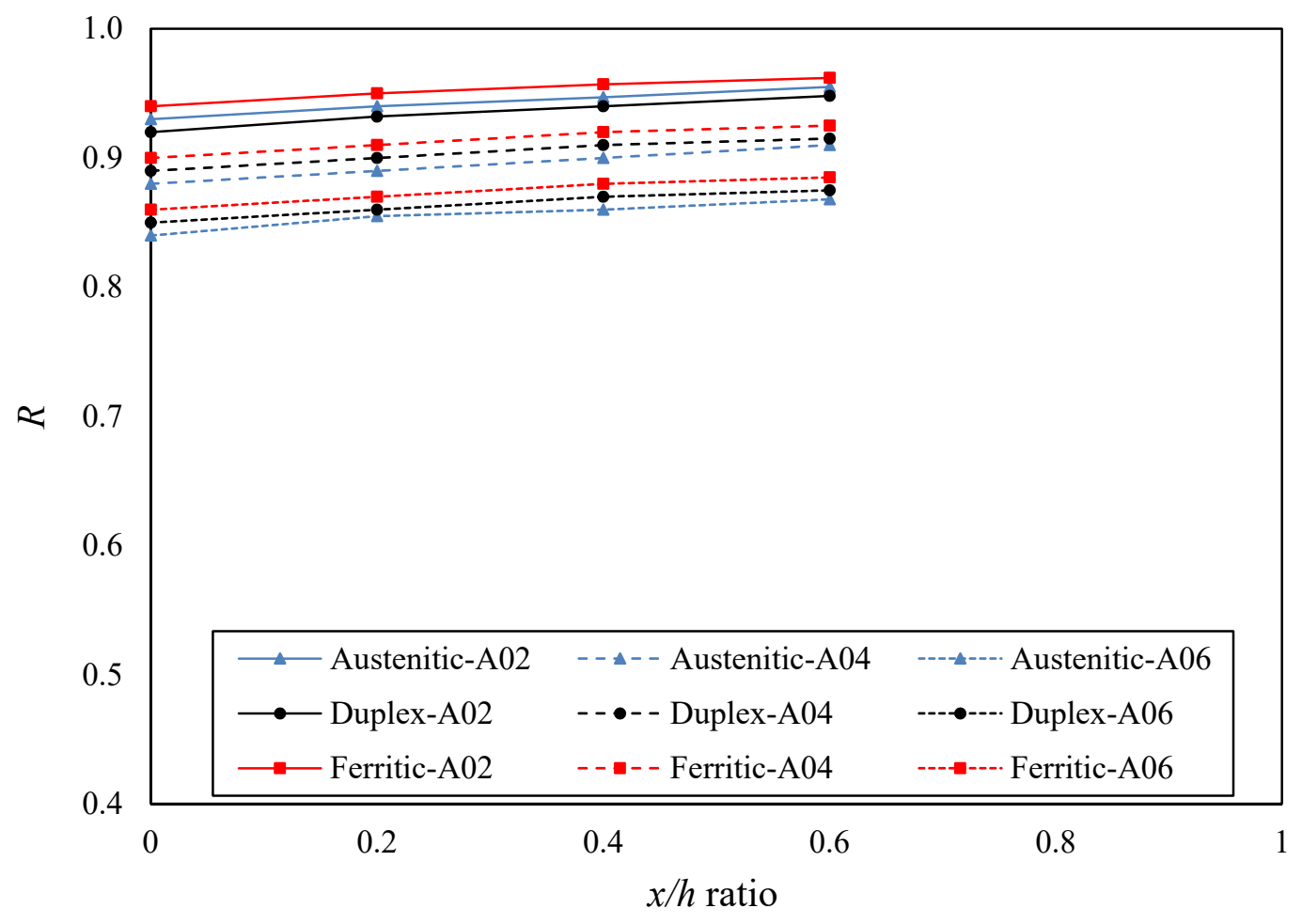

(c) with $x / h$ for offset circular web perforation

Fig. 8. Variation in reduction factors for $\mathrm{C} 142$ section for the case of flanges unfastened to bearing plates 


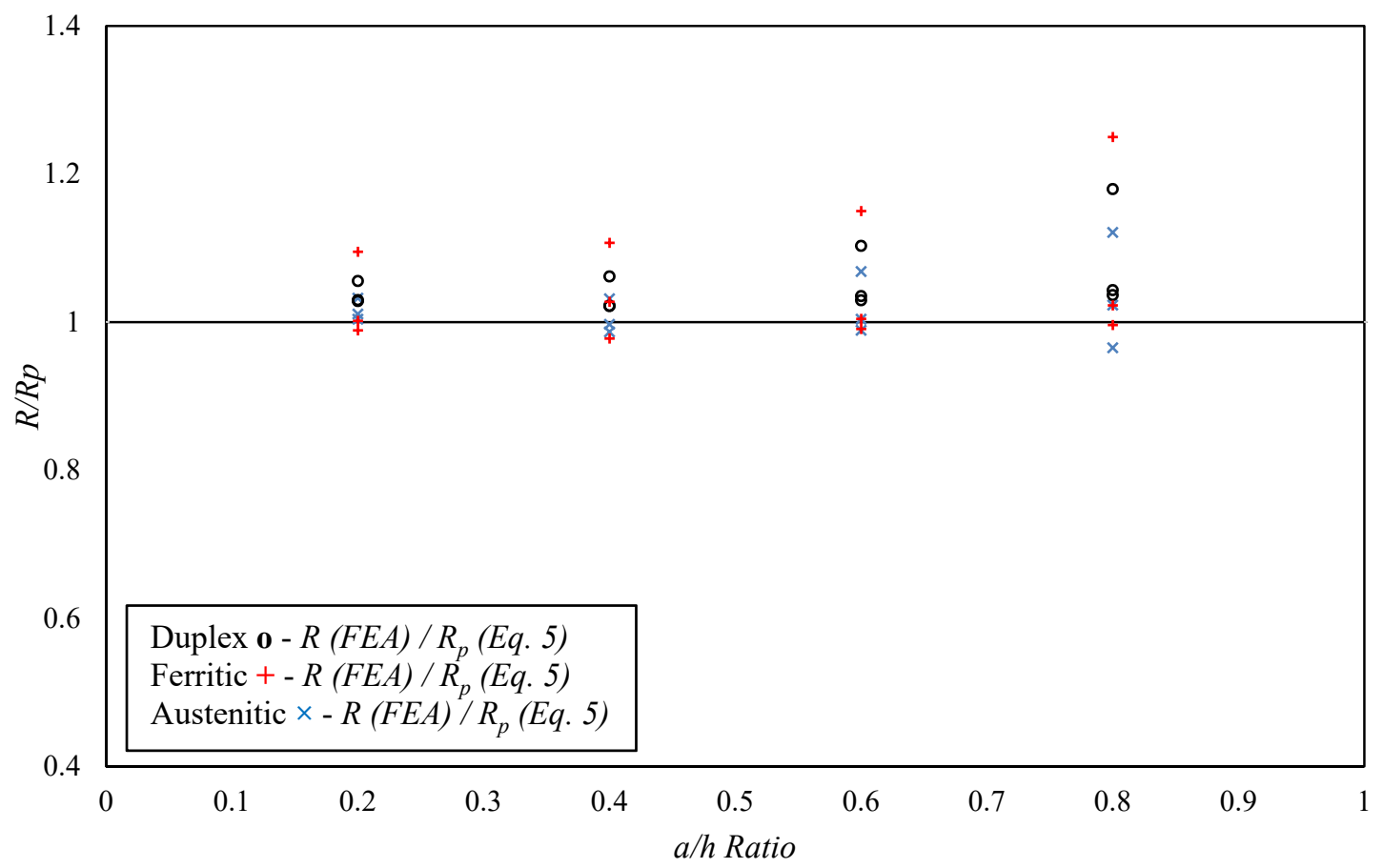

(a) For the case of flanges unfastened to bearing plates

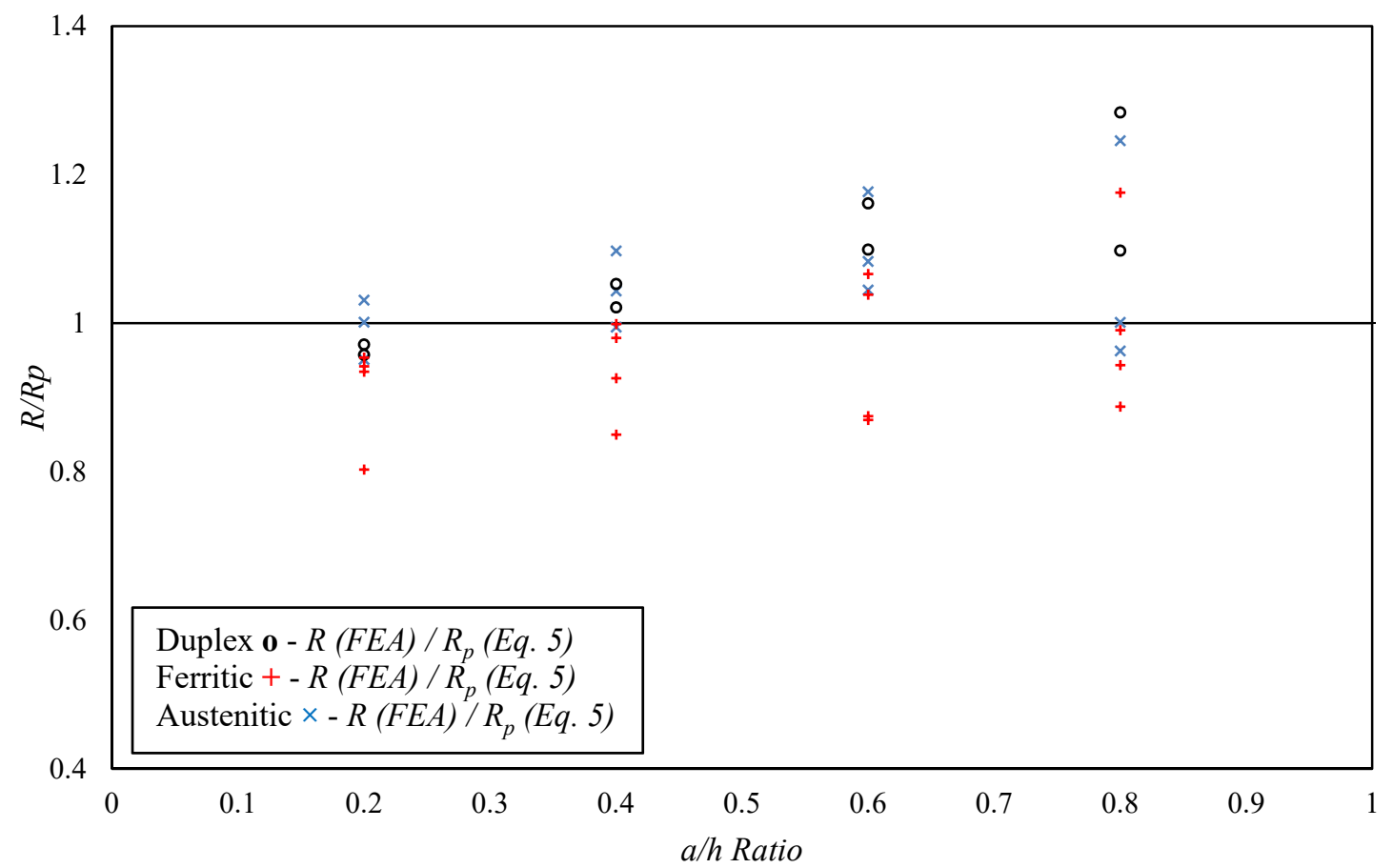

(b) For the case of flanges fastened to bearing plates

Fig. 9. Comparison of strength reduction factor for $\mathrm{C} 142$ section with centered circular web perforation 


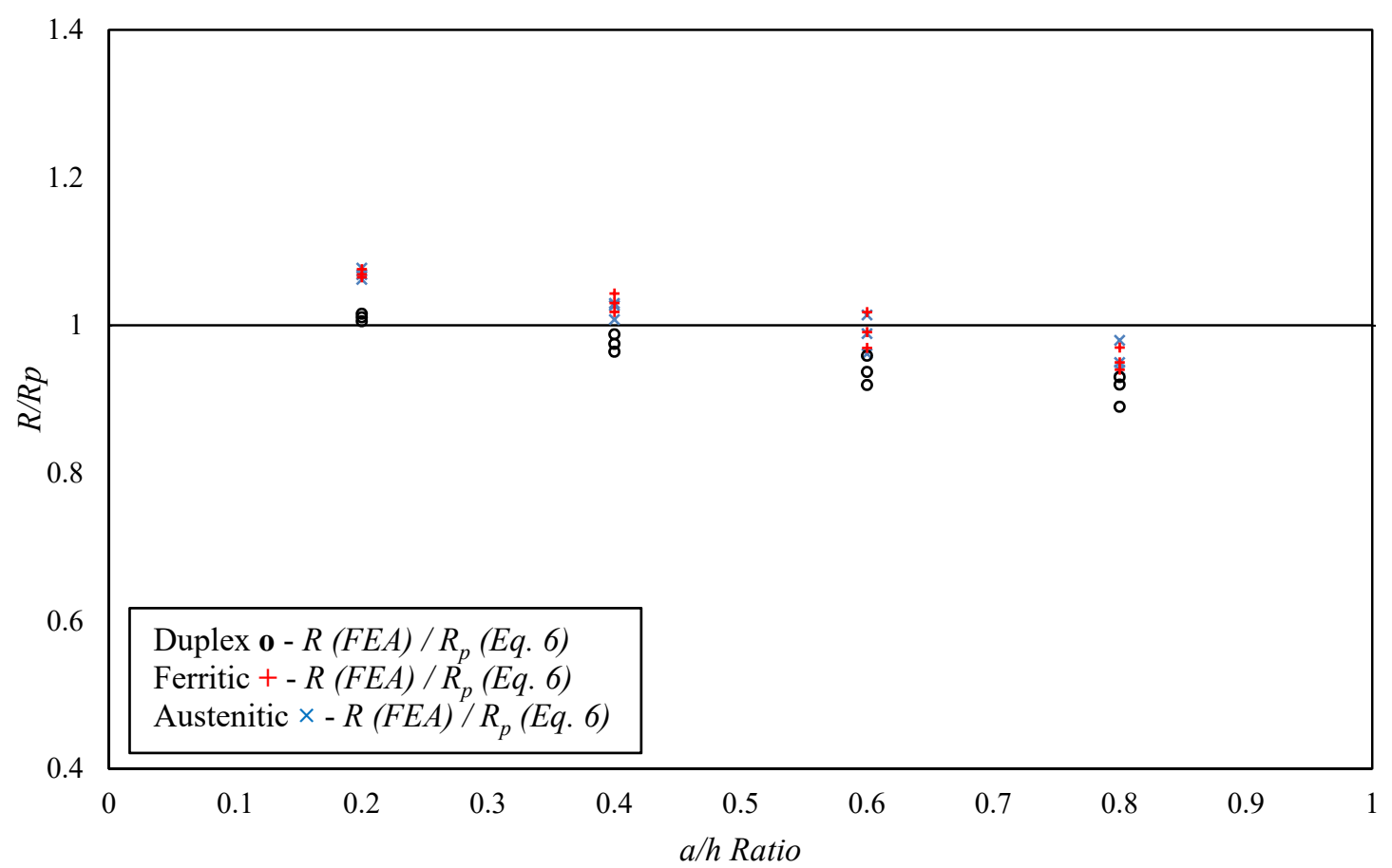

(a) the case of flanges unfastened to bearing plates

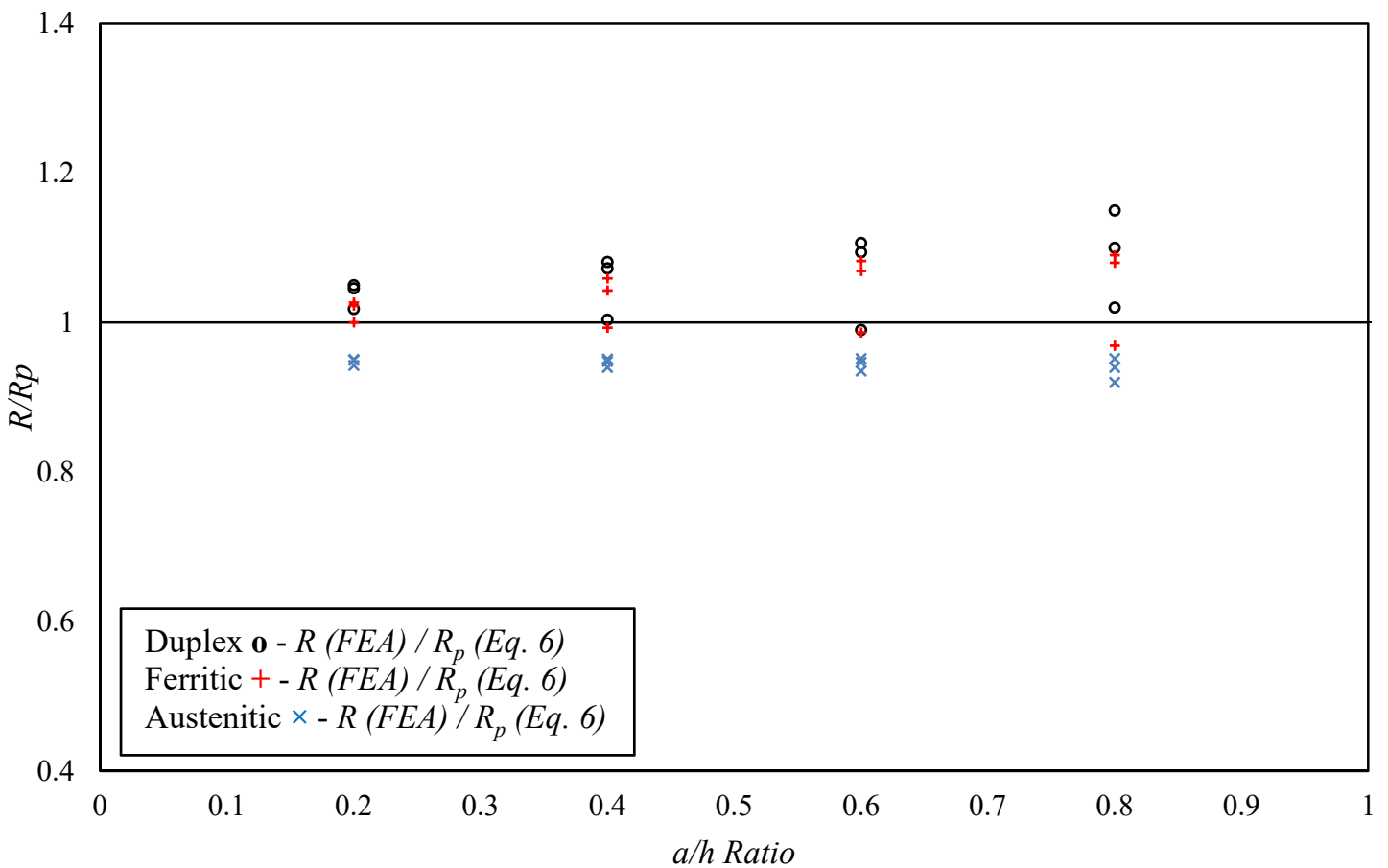

(b) the case of flanges fastened to bearing plates

Fig. 10. Comparison of strength reduction factor for $\mathrm{C} 142$ section with offset circular web perforation 


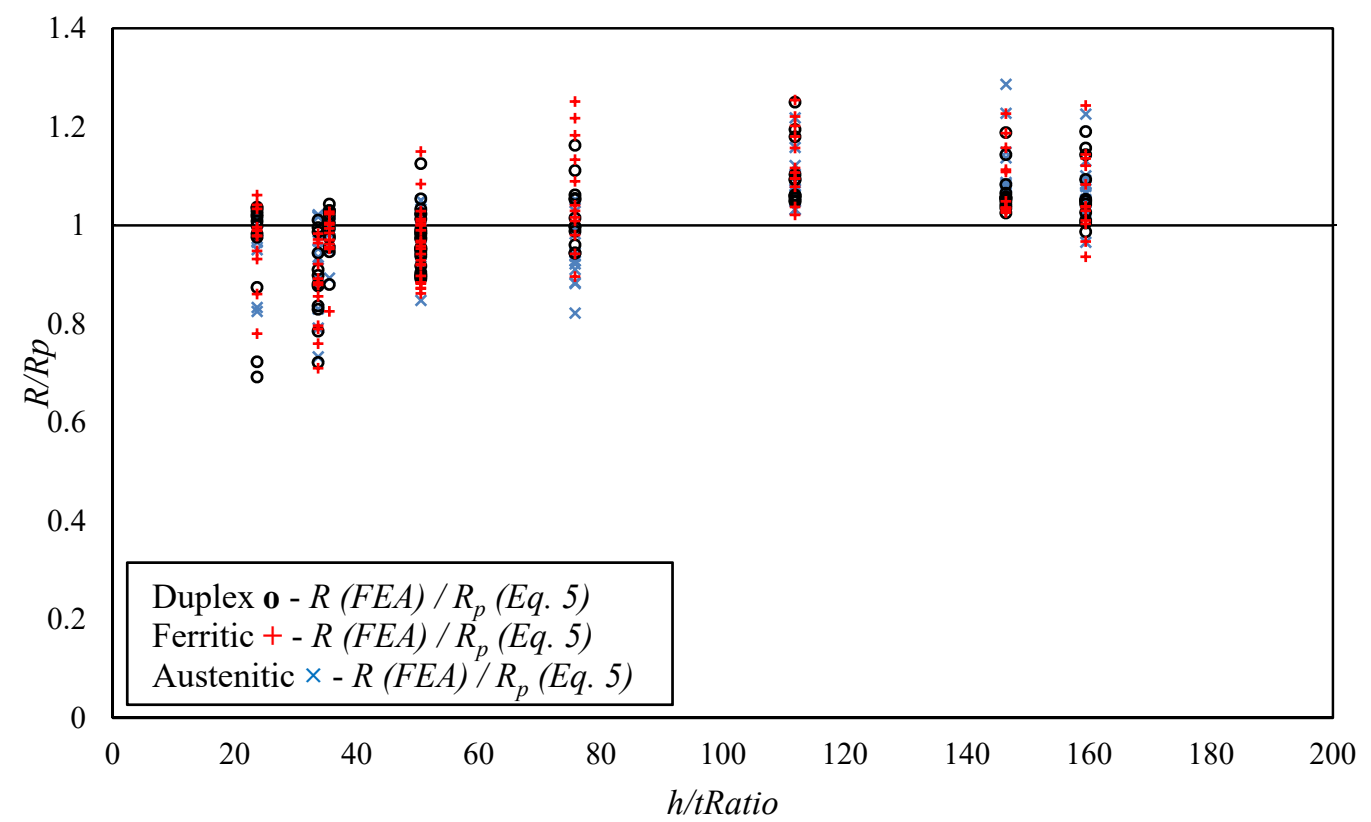

(a) For the case of flanges unfastened to bearing plates

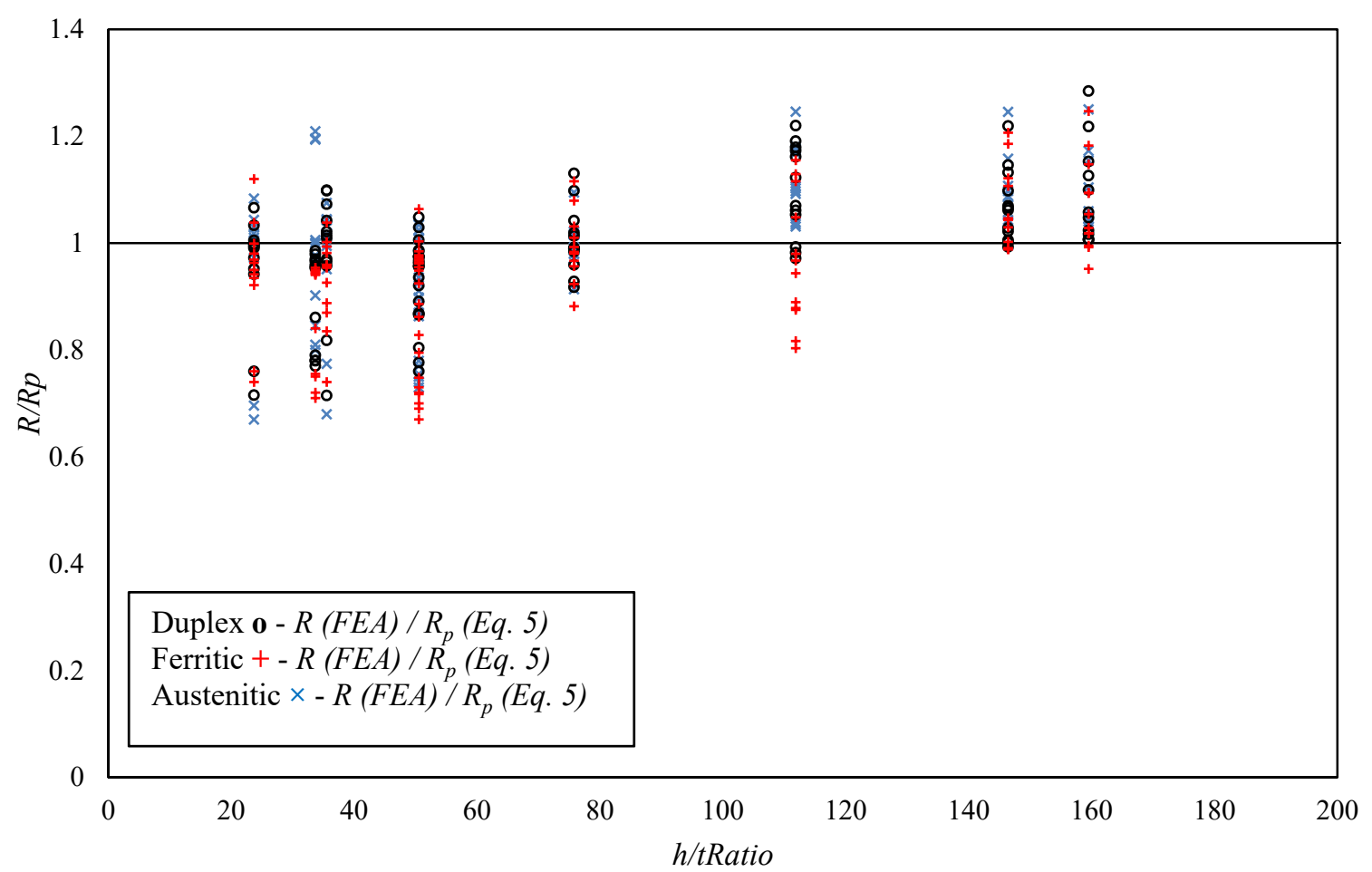

(b) For the case of flanges fastened to bearing plates

Fig. 11. Comparison of strength reduction factor for sections with centered circular web perforation 


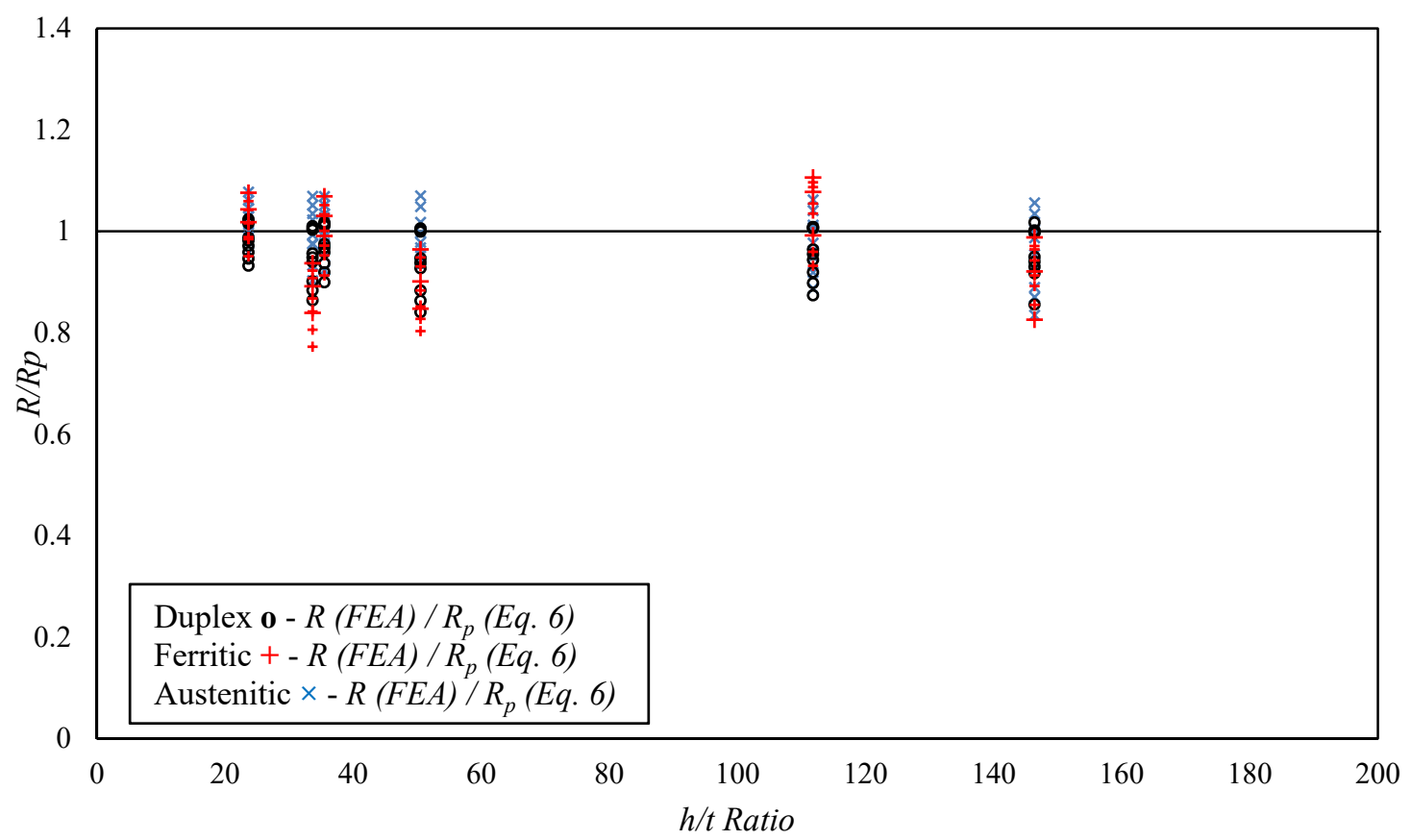

(a) For the case of flanges unfastened to bearing plates

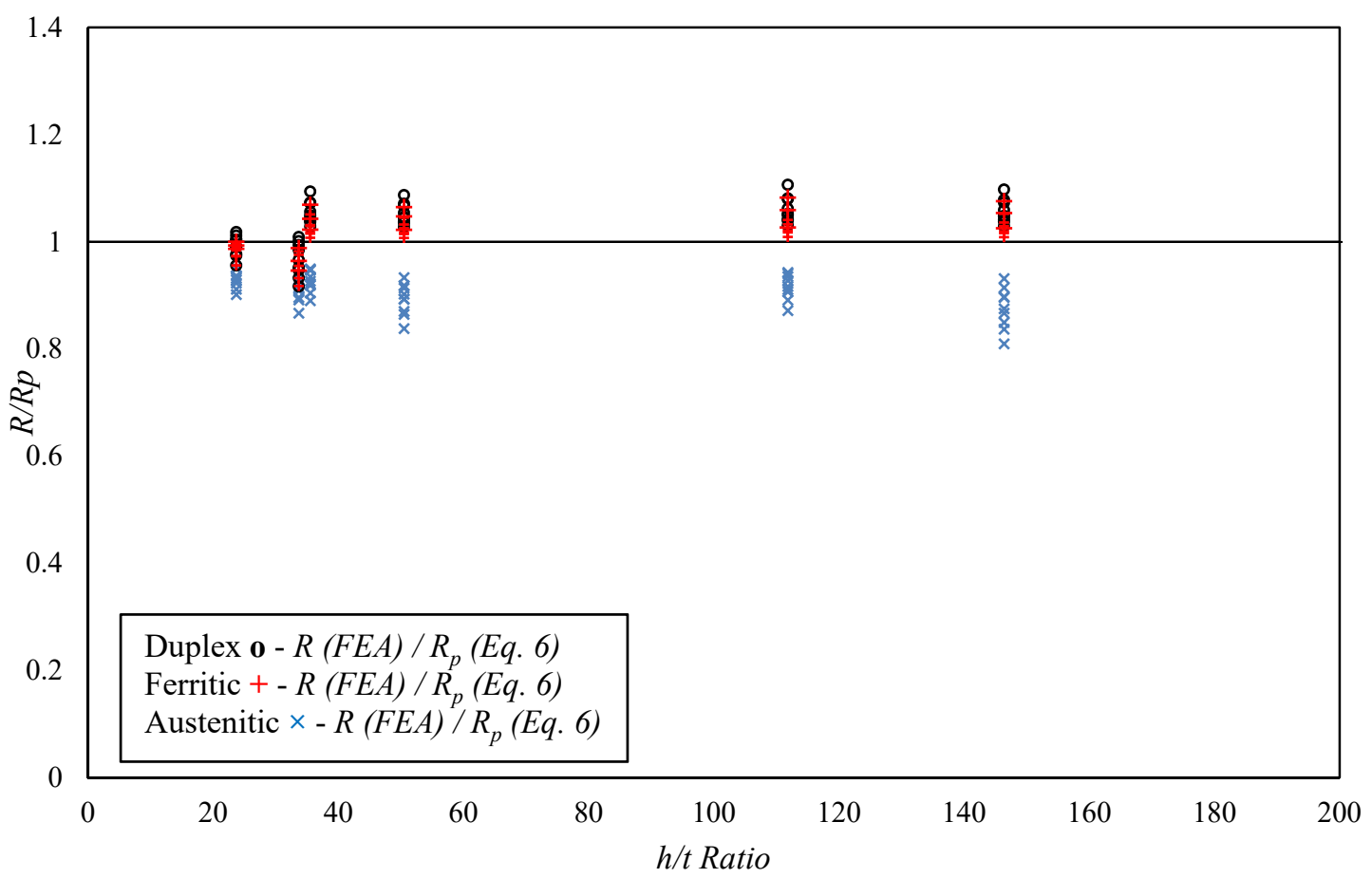

(b) For the case of flanges fastened to bearing plates

Fig. 12. Comparison of strength reduction factor for sections with offset circular web perforation 